\title{
Connections to distant knowledge: Interpersonal ties between more- and less-developed countries
}

\section{Daniel Z Levin ${ }^{1}$ and Helena Barnard ${ }^{2}$}

\footnotetext{
'Management and Global Business Department, Rutgers Business School, Rutgers University, Newark, NI, USA; ${ }^{2}$ Gordon Institute of Business Science, University of Pretoria, Sandton, South Africa

email: barnardh@gibs.co.za

Correspondence:

Daniel Z. Levin, Management and Global Business Department, Rutgers Business School-Newark and New Brunswick, Rutgers University, 1 Washington Park, Newark, NJ 07102, USA.

Tel: +1 (973) 353-5983;

Fax: +1 (973) 353-1664;

email: levin@business.rutgers.edu
}

\begin{abstract}
Less-developed countries benefit from being connected to technologically and economically advanced countries. The well-documented mechanisms for this cross-national flow of knowledge all involve interfirm connections, such as trade, foreign direct investment (FDI), and alliances. We examine the potential of a different mechanism - interpersonal ties abroad - that has only recently become practicable, owing to advances in communication and transportation technologies, globalization, and increased migration. We investigate when business knowledge obtained from interpersonal ties in more-developed countries is more useful than locally sourced knowledge. Using a sample of South African managers, we find that knowledge from more-developed countries is not always more useful. Rather, overseas knowledge is preferable when novel and accessible: that is, when new-to-the-industry knowledge is needed, when there is already a strong tie, and when the knowledge does not involve a long discussion. Conversely, local knowledge is preferable when new-to-the-industry knowledge is not needed, when the interpersonal tie is a weak tie, and when a longer discussion is warranted. This study demonstrates the value of connections between individuals in countries at different levels of development as sources of useful knowledge, and suggests that international business research will benefit from exploring further the networks of individuals in addition to those of firms.
\end{abstract}

Keywords: diaspora; economic upgrading; emerging markets/countries/economies; knowledge transfer; long-distance communication; social networks

\section{INTRODUCTION}

I will fetch my knowledge from afar. (Job 36:3)

This paper on interpersonal ties abroad makes three contributions. First, it contributes to the body of literature on how less-developed countries use international connections to upgrade their capabilities. Our second contribution is to develop a more detailed understanding of the process of cross-border knowledge transfer. We find that knowledge from more-developed countries is not always more useful than local knowledge. However, we identify when it is more useful to seek business knowledge from ties abroad: specifically, such knowledge is more useful when it is new to an industry, and when it 
is accessible to the seekers of that knowledge. Our third and perhaps main contribution is that our research focuses not on connections between firms, but instead on interpersonal connections: how businesspeople mobilize their personal networks in more-developed countries to access useful business knowledge. In so doing, we contribute to an emerging body of research on diasporas and social networks in international business.

The recent surge of literature on diasporas takes as a point of departure that a diaspora acts as a link between two different countries. That link, often between countries at different levels of development, can facilitate the sharing of capital (Flisi \& Murat, 2011; Mullings, 2011), technical knowledge (Agrawal, Kapur, McHale, \& Oettl, 2011; Oettl \& Agrawal, 2008), and expectations of how business should be conducted (Riddle \& Brinkerhoff, 2011). The current paper, which uses a quasi-experimental design, contributes to that literature by identifying when managers in a less-developed country benefit from the perspective of their compatriots now living in a more-developed country.

The movement of people between different sites has long been recognized as a potential mechanism for the diffusion of knowledge to a less-developed country (Bell \& Pavitt, 1997). Although interpersonal and interorganizational networks are of course intertwined (Chetty \& Agndal, 2008), research on how international business can contribute to upgrading has long focused on ties between firms rather than on ties between individuals. Indeed, the best-described mechanism through which contact with a technologically advanced country can lead to upgrading is still FDI and the multinational corporation (MNC) (Blomström \& Kokko, 1998; Driffield, Love, \& Menghinello, 2009; Marin \& Bell, 2006; Meyer \& Sinani, 2009; Narula \& Dunning, 2000). Other mechanisms, such as exports (Lall, 1998), or joint ventures and acquisitions (Bresman, Birkinshaw, \& Nobel, 1999; Gubbi, Aulakh, Ray, Sarkar, \& Chittoor, 2010), also emphasize contact between firms.

However, since the reframing of migration as a form of "brain circulation" (Saxenian, 2005) rather than simply brain drain, there has been a growing body of evidence on how diasporas and migration could be mechanisms for cross-national knowledge diffusion. Saxenian $(2002,2005)$ pioneered work on what was later termed "returnees": people who move back to less-developed home countries after gaining education and work experience in more-developed countries. Returnees' knowledge of countries at different levels of technological and economical development allows them to act as a bridge between those different worlds, and the evidence is that they can act as sources of potentially useful knowledge, not only in their former host but also in their home countries (Saxenian \& Hsu, 2001; Vang \& Overby, 2006). Subsequent research confirms that returnees facilitate knowledge transfer (Filatotchev, Liu, Buck, \& Wright, 2009), and also that their presence is positively correlated with innovation in the less-developed country (Liu, Lu, Filatotchev, Buck, \& Wright, 2010).

Saxenian (2006) also coined the term "argonaut" to refer to people constantly traveling back and forth between their home and an adopted country. A similar concept, coined by Madhavan and Iriyama (2009), is that of "transnational technical communities" - that is, highly skilled immigrants who remain active in both their host and home countries. In their study of US-based venture capitalists, Madhavan and Iriyama find that transnational technical communities facilitate the globalization of venture capital.

Such research on "returnees", "argonauts", and the like is concerned with knowledge that is transferred when people physically move between countries. Yet there is also evidence that people need not spend time living or working in the same country the existence of interpersonal networks is enough. For example, Kerr (2008) finds that knowledge diffuses from ethnic scientists and entrepreneurs in the United States back to their home countries, increasing manufacturing output in those countries. The notion that knowledge can flow through interpersonal ties, even when people are not co-located, is important not only in a diaspora context, but also more generally. Thus Almeida, Hohberger, and Parada (2011) document the value to firms of scientific collaborations between individuals, whether in other firms or in institutions such as universities.

Moreover, in an increasingly globalizing world, it seems likely that interpersonal cross-border contact will increase, and with it, the need to extend our understanding of how knowledge is transferred when people are not co-located. Thus we regard the diaspora also as a useful lens to understand the link between knowledge transfer and interpersonal ties more generally. Furthermore, apart from the body of research on expatriates working within MNCs (e.g., Oddou \& Mendenhall, 1991), the role of individuals as mechanisms for knowledge transfer in international business research has only recently started to receive significant scholarly attention (e.g., in the 
work of Agndal \& Axelsson, 2002; Almeida et al., 2011; Almeida, Phene, \& Li, 2010; Chetty \& Agndal, 2008; Madhavan \& Iriyama, 2009). Our paper also contributes to that literature.

Whereas, in the past, interpersonal ties abroad were generally hard to establish and maintain, modern transportation and communication technologies have brought them within reach. With these changes, the functioning of personal networks per se has increasingly been a topic of investigation of international business research. Ellis already in 2000 highlighted the role of interpersonal ties in identifying export opportunities, and in a study of entrepreneurs in four Chinese cities, Ellis (2011) finds that the use of social ties as a way to identify international opportunities increases with international experience, and also that the opportunities recognized through the use of social ties are economically more important than those found through other means (e.g., trade fairs).

In their study of the Argentine automotive industry, McDermott and Corredoira (2010) find that social ties are beneficial, but not uniformly so. The effects are different for suppliers at different tiers: the benefits of social ties were stronger for higher-tier suppliers, and benefits were also stronger for links to local suppliers and customers than for links to nonmarket institutions such as universities and foundations. The work of McDermott and Corredoira (2010) differs from other research in that they examine (although not explicitly) the effects of both international and local ties in a less-developed country. Their findings suggest that useful knowledge in a less-developed country can also be obtained locally, not only from partners in the developed world. In other words, their evidence challenges the stylized notion of more-developed countries as the sole competent providers of useful knowledge for firms or managers in less-developed countries.

Indeed, although less-developed countries are characterized by various institutional weaknesses (Doner, Ritchie, \& Slater, 2005), there is also evidence that local knowledge matters, for example, in the emerging literature on local innovations at the so-called "base of the pyramid" - that is, among consumers who live on less than US\$2 a day (Kaplinsky et al., 2009; London \& Hart, 2004). The base-of-thepyramid context is a very specific one, but local knowledge in many different contexts is often of value. For example, it is likely that valuable knowledge circulates in less-developed countries not only about how to succeed in local markets, but also about better and worse strategies for dealing with wealthier markets. In addition, studies on how less-developed countries use international connections to upgrade capabilities emphasize the considerable effort required by local entities (Kim, 1998; Marin \& Bell, 2006), because knowledge from abroad may be irrelevant, or may need to be extensively adapted.

However, we do not know under which conditions knowledge from abroad is better than knowledge sourced locally. The so-far sparse body of work on interpersonal networks in international business tends to examine how a single type of tie (e.g., returnee emigrant or transnational technical community) provides access to global opportunities. Yet it increasingly happens that people have ties with businesspeople both locally and abroad, and can source knowledge from either. Thus our research question is to uncover when it is advantageous for managers to seek business knowledge from interpersonal ties abroad vs locally.

\section{HYPOTHESES}

The usefulness of knowledge received is a broad concept with multiple drivers and is perhaps best compared with something such as firm performance, where various conceptually and empirically distinct drivers all play a role in determining how well a firm performs. We argue that knowledge sourced both locally and abroad can potentially be useful, but that knowledge sourced through ties abroad is especially beneficial in three cases: first, when it is novel; second, when there are strong ties between the knowledge seeker and the knowledge provider; and finally, when it can be shared in a relatively short exchange. The first point, on the novelty of knowledge, builds on previous research on the importance of international business connections as sources of new knowledge and technology. The second and third points consider some implications of the knowledge seeker and knowledge provider not being colocated, and introduce to international business research the hitherto underexamined dimension of the accessibility of knowledge from abroad.

\section{The Novelty of Knowledge}

A point of departure of the literature on international business and economic upgrading is that knowledge from abroad is valuable because - and to the extent that - it is new. For example, MNCs, through their subsidiaries in less-developed countries, are argued to be a more likely source of novel and non-commoditized knowledge than market-based avenues such as exports or licensing, as cutting-edge knowledge is rarely available on the 
market (Lall, 2001; Narula \& Dunning, 2000). In other words, international business connections are valuable not simply because they are a conduit for knowledge, but specifically because they can provide access to knowledge that is new to a given context.

Ellis (2011) highlights the distinction between a business network (of which a subsidiary and a headquarters could be members, and where the emphasis is on the "bigger picture") and a social network (where interpersonal ties connect parties). Although they operate at different levels, both types of networks can provide their members with privileged access to knowledge. Interpersonal ties across national boundaries are similar to subsidiary-parent relationships in that they provide the additional advantage (over local ties) of acting as possible sources of new, non-commoditized knowledge. There may be instances that do not follow this overall trend: for example, a local may happen to be an expert in a particular area that a contact abroad does not know about. But even given these notable exceptions, managers in a less-developed country are generally more likely to find their ties abroad (rather than their local ties) particularly useful when they seek new-to-the-industry knowledge. Thus we would hypothesize:

Hypothesis 1: The more that a manager needs new-to-the-industry knowledge, the more useful it will be to seek knowledge from contacts abroad as opposed to locals.

\section{The Accessibility of Knowledge}

When considering the nature of knowledge, the comparison between the organizational network of a multinational (where a subsidiary can typically access the knowledge of other subsidiaries and/or headquarters) and the personal network of an individual is instructive: Both can be good sources of novel knowledge. But the same cannot be said about the accessibility of knowledge, and this difference relates to the nature of the two types of networks.

Once an MNC has identified sources of valuable knowledge, it is in the interest of the corporation to try to ensure that that knowledge is shared as widely as possible within the MNC. Whether through strengthening ties between different organizational units or even, if needed, through strengthening ties beyond the MNC, the evidence suggests that MNCs will take steps to facilitate the effective transfer of knowledge. For example, Criscuolo (2005) records that scientists in pharmaceutical industries go abroad for up to a year to understand advances at other subsidiaries. Similarly, Zhao, Anand, and Mitchell (2004) document various cross-border visits to help Chinese automakers understand the technology of their partners in the United States and Germany. One program involved 41 Chinese managers and engineers going to Germany for a year to learn the latest technologies. While the expense of such visits may be an issue for many firms, the point is that multinationals can and do provide resources to help make knowledge more accessible to their various subsidiaries and joint-venture partners.

Interpersonal networks, however, do not have the same level of resources. A manager who asks a former colleague, college roommate, or mentor now living in a different country for knowledge does not have the option of a 6-month stay abroad to help him or her to make sense of the new knowledge. For this reason, when accessing knowledge through an interpersonal network abroad, the accessibility of the knowledge is essential. Unless it can be successfully shared, it will not be of much use to the knowledge seeker. In exploring the accessibility of knowledge from abroad, we consider first who is involved in sharing knowledge, and second how knowledge transfer takes place.

Knowledge can be more or less accessible based on the nature of the ties between whom the knowledge is exchanged. Tie strength itself has been shown in past research to contain conflicting effects that operate at cross-purposes (e.g., Levin \& Cross, 2004; Levin, Walter, \& Murnighan, 2011). On the one hand, weak ties - relationships where the two people have never met or do not know each other well tend to provide more novelty, but on the other hand provide less willingness to listen and share. However, these effects change somewhat when considering ties in a local vs international context.

Weak ties tend to provide novel knowledge and fresh ideas, because weak ties generally operate in different circles (Granovetter, 1973; Levin \& Cross, 2004; Levin et al., 2011). Because local weak ties provide better access to social circles beyond those of the respondent and his or her regular advisors, the knowledge is less likely to be redundant with what the respondent already knows. Moreover, within a local context, the differences in willingness to listen and share are not likely to be all that large, and certainly not enough to counteract the valuable non-redundancy that the local weak ties can provide. Consistent with prior evidence, when considering knowledge seeking and knowledge giving only among locals, we would expect knowledge from weak-tie local contacts to be more useful than from stronger local ties with their more redundant knowledge. 
This is unlikely to be the case when considering ties abroad. We argue that substantial non-redundant knowledge is likely to be found for both weak and strong ties abroad, but that the willingness to listen and share will be much more critical in distinguishing strong from weak ties abroad. As regards novelty and non-redundancy, a manager's contacts abroad, whether they are weakly or strongly connected to the knowledge seeker, are by definition active in a different country and thus provide extensive access to knowledge that is likely to be novel to the manager back in the home country. Obviously, not every contact abroad will have novel knowledge that is relevant to the knowledge seeker's problem, but the odds should be significantly higher than locally. As a result, strong ties to contacts abroad are just as likely to be potential sources of novel knowledge as are weaker ties abroad - maybe slightly less so, but likely not enough to make a meaningful difference.

However, because of the challenges presented by the fact that they are not co-located, weak-tie contacts abroad may be particularly unmotivated to help. First, knowledge sharing itself is complex, as it does not necessarily happen in a single conversation but can involve multiple modalities and time periods - for example, initial contract through email, followed by a phone call, perhaps the exchange of some documents, and then another call. International interactions often require even more effort, such as logistical and coordination issues due to different time zones, schedules and so forth. Moreover, weak ties abroad are likely to lack a shared context, norms, or the possibility of third-party sanctions for ignoring or mistreating a knowledge seeker, and there are also fewer possible benefits for the provider, such as the likelihood of reciprocal help or an improved reputation, to helping someone living in another country. Thus we would expect contacts abroad to be much less motivated to share their knowledge if they barely know the knowledge seeker. As a result, we would expect these weaker ties abroad to be less useful overall their access to novel knowledge largely untapped. In contrast, when there already is a close bond between two individuals, even if they are living in different countries, we would expect the knowledge provider to be motivated to make the effort to share his or her novel knowledge. Thus we would hypothesize:

Hypothesis 2: Tie strength will moderate the impact of knowledge seeking on the receipt of useful knowledge, such that stronger ties to contacts abroad will be more useful than weaker ties to contacts abroad, but weaker ties to locals will be more useful than stronger ties to locals.

In sum, we extend existing theory on tie strength, including its dual nature (Levin \& Cross, 2004; Levin et al., 2011), to a cross-border context, arguing that one aspect of tie strength (non-redundancy - i.e., a benefit of weak ties) will be more important locally, whereas the other aspect of tie strength (willingness to share - i.e., a benefit of strong ties) will be more important for ties abroad.

Also related to the accessibility of knowledge seeking abroad is the length of knowledge-seeking interactions. Specifically, knowledge obtained is considered useful or not depending on the value it brings to the knowledge seeker in doing his or her work, regardless of the amount of time it takes to obtain it, and most studies focus on the absolute value of knowledge obtained. However, because managers operate under time constraints and with competing demands, the efficiency of obtaining knowledge, which takes into account both the usefulness of the knowledge and the cost in terms of the time it takes to obtain it, is also relevant. Longer interactions are indeed associated with providing more value, partly because people choose to continue interactions that are proving valuable, and partly because longer interactions allow for more valuable knowledge to emerge and/or be created (Levin et al., 2011). This benefit of longer interactions is true for local ties, and it is true for ties abroad. Nevertheless, despite their benefits, longer interactions - by definition - come at a cost: they are time consuming. So if an interaction can be both useful and short, then that is usually a good thing.

We argue that considerations of efficiency shape the benefits obtained from advice providers locally vs abroad. Ties abroad as a rule have access to more novel knowledge, and if an interaction can be short, then this will tend to favor them over local ties. If knowledge seeking were costless, then it can be expected that the inputs of an advice provider abroad, per a given unit of time spent, would always tend to be more useful than advice from local ties. But the benefits of getting knowledge from abroad that is, those novel and useful ideas - must be considered in the context of the higher cost of obtaining this knowledge. The higher costs of obtaining knowledge from abroad are incurred, first, because the knowledge provider and knowledge seeker are not physically co-located, and, second, 
because such knowledge is more likely to be embedded in a less-familiar context.

First, people benefit from physical co-presence (e.g., Leamer \& Storper, 2001; Rosenkopf \& Almeida, 2003). As much as advances in telecommunications have resulted in a "powerful imitation of closeness" (Leamer \& Storper, 2001: 652) and made it easier to communicate halfway across the globe, there remain serious limitations to telecommunications technology. As a result, the greater logistical complexity of engaging with a person abroad can weigh down the benefits of extended interactions with advice providers from abroad. For example, it is harder to cocreate new knowledge through an intense back-andforth exchange, to spend an extra hour beyond what was scheduled, or to go back to someone to clarify something afterwards. Such long and involved interactions are more likely to be useful when consulting local contacts, where there are fewer logistical constraints.

Second, knowledge requiring a long interaction to convey is often embedded in a unique context that may differ in important ways from what the knowledge seeker is confronting. Such contextually embedded ideas take a long time to explain and be fully understood (Szulanski \& Jensen, 2006), they may not "translate" well into a new context, and hence are less likely to be very useful in the end. For example, if a business solution will work only if government regulators are supportive, if the company's supply chain is configured a certain way, or if employees are familiar with a certain computer system, then it is unlikely that it will translate well internationally into a completely different context. If the knowledge can be transferred quickly, though, then it may be the kind of knowledge - for example, less complicated logistically and less contextually embedded - that is especially well suited for knowledge seeking abroad.

The point, of course, is not that spending more time discussing such knowledge will be harmful - on the contrary, taking more time to explain something, even something relatively straightforward, is almost always helpful - but it may not be efficient. That is, we argue that the longer the interaction needs to be, the less it plays to the strengths of knowledge seeking from interpersonal ties abroad namely, quick and easy access to novel knowledge and the better off the knowledge seeker might have been to consult someone locally instead. Indeed, beyond a certain point, local contacts are likely to be better sources of advice. That is to say, the benefits that accrue to longer interactions will come more rapidly with local ties, as it is easier to tap into and co-create knowledge with someone locally. To be sure, a longer interaction generally provides more benefits, even with a tie abroad, but in an interaction with a tie abroad, it will take longer to "extract" the same level of added benefit than it would locally. After all, local interactions, benefiting from the possibility of both physical co-presence and a greater shared context, lend themselves relatively well to longer and more involved interactions. We therefore hypothesize:

Hypothesis 3: The longer the interaction, the more useful it will be, but this effect will be larger with local contacts than with those abroad.

\section{METHODS}

\section{Overview}

To address our research question on the potential value of interpersonal ties as a possible mechanism for international knowledge transfer, we use a quasiexperimental research design. That is, our interest is not in which knowledge-gathering strategies managers do or do not currently use (although this could be an interesting future research question), but rather on what the potential value would be if managers were to seek business knowledge using interpersonal ties abroad. With quasi-experimental design, one of the central tensions that must be managed is whether "the internal validity costs of eschewing deliberate manipulation and more confident causal inferences are worth the gains for external validity of having an initially more representative sample" (Cook \& Campbell, 1979: 90). We used a range of strategies to minimize trade-offs between internal and external validity.

The data for this study were gathered in South Africa, a country that is behind the technological frontier along a number of metrics (Archibugi, Denni, \& Filippetti, 2009) and similar to a range of other leading less-developed countries, such as Argentina, Brazil, Indonesia, and Thailand. We asked 249 South African middle managers - who, in addition to working full time, were also participants in a part-time graduate-level program at a South African business school - to think of "a current, major project at work that has real significance for your career", and then to "seek the advice of outside people to improve your performance on this work project, both locals and people who are currently based abroad". In the terminology of Ettlinger (2003: 146), we used a "microspace" approach: We used as 
starting point the "universes of interaction" of the managers, and asked them to identify and consult from that universe one South African living and working in South Africa and one South African living and working abroad in a more-developed country, which by their own choosing turned out to be mostly the United Kingdom (38\%), the United States (25\%), and Australia (19\%). Respondents could approach multiple potential knowledge sources before deciding on which one local source and which one source abroad they would report.

For the sake of internal validity, participants were given three guidelines: First, we kept nationality constant for both types of ties, thereby allowing us to rule out various alternative explanations. (This design is also in keeping with the reality that most managers in less-developed countries have personal ties internationally primarily to compatriots living abroad either as expatriates or emigrants.) Second, participants were expected to contact individuals whose "skills or knowledge are relevant to your efforts on your chosen work project". Third, participants were restricted to sources who had not already been consulted on the chosen work project. By having both types of ties be outside the manager's usual advice network for that project, various alternative explanations could be ruled out. In particular, this design helped mitigate a home-country bias, because respondents had to make the effort to identify potentially useful knowledge sources, both locally and abroad, beyond those who had already been involved. Participants, after consulting their two contacts, submitted a short essay describing their experiences.

Other than these guidelines, participants - just as in an unprompted, business-knowledge-seeking situation (e.g., Levin et al., 2011) - were given the freedom to identify any aspect of their work project on which they wanted knowledge, and had free choice in terms of which contacts they sought out and how they interacted with them. This methodological decision meant that the two ties could have a very different relationship to the knowledge seeker (e.g., friend vs ex-colleague) and could offer very different types of knowledge (e.g., handling an organizational change vs technical details on a new compliance process). The main gain of this approach is that it increases external validity: that is, the research is likely to capture a wide range of knowledge-seeking behavior, directed by the managers themselves. To illustrate this point, we randomly selected 15 respondent essays (see below) and describe qualitatively in Table 1 the nature of both ties, their expertise, and the knowledge sought from each by the respondent.

From their essays it was clear that participants had an inclusive definition of what constitutes useful knowledge. Knowledge was sometimes deemed useful because it was novel, and sometimes because it validated existing ideas:

What made him one of the "best" is that he wasn't afraid to try something different.

After we finished our conversation, I was pleased with the progress, because just answering his questions, gave me an opportunity to think through some of the challenges. He then email[ed] me with his input and most of the ideas that he echoed were part of what was in my plan, so that helped as a way of validating my ideas.

Participants also valued knowledge sometimes because they were able to get considerable time and attention from the advice giver, and sometimes because the interaction was quite efficient:

I initiated the session by taking [her] through the problem statement, explaining what I thought would be an appropriate approach to tackling the problem and clarifying any questions she had regarding the project and/or the outcome I desired. We also spent a fair amount of time on how ABC actually used their current processes and project management methodology. I also shared my secondary outcome of facilitating discussion between the TLs and the CRMs and the cycle of lack of accountability and reinforcement of this behavior that prevailed. ... We brainstormed a fair amount of radical applications.

He paid attention to what I was saying and did not diverge into some other conversation. It was like he already knew what I would ask and had already prepared responses. The conversation lasted about 15 minutes but it was very helpful.

In short, the qualitative evidence suggested that we needed to use an inclusive approach in how we conceptualized the usefulness of knowledge received.

After having completed the essays, participants received a voluntary, confidential email survey asking about the two people as well as some general questions. Although consulting the two people and subsequently writing an essay about the knowledgeseeking process were course requirements, respondents were told, truthfully, that the course instructor would never see any of the email surveys and would not know who did or did not complete them. The survey questions probed the process of seeking knowledge, the nature of knowledge sought, and respondents' relationships with knowledge providers. Where possible, items were taken from existing scales.

The survey questions, as well as the overall research design, were based on preliminary results 


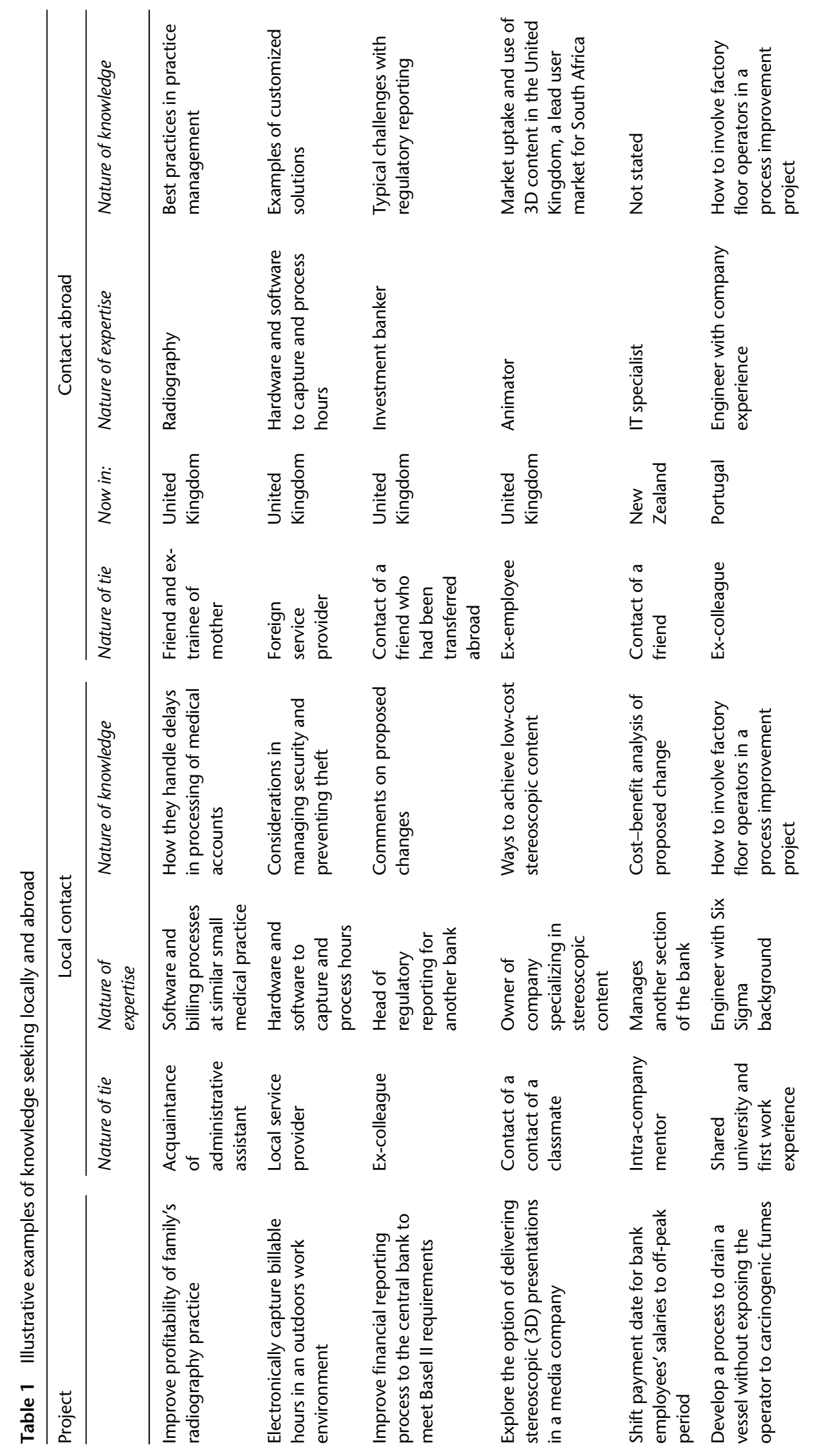




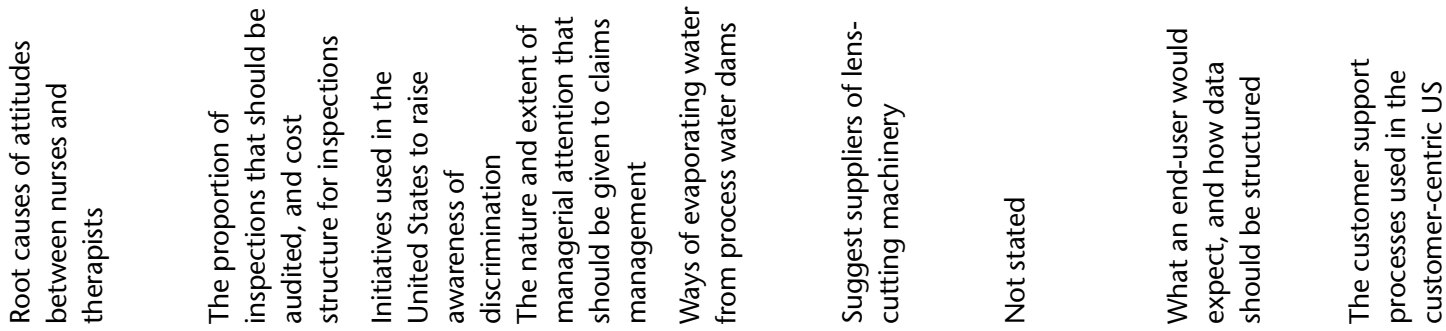

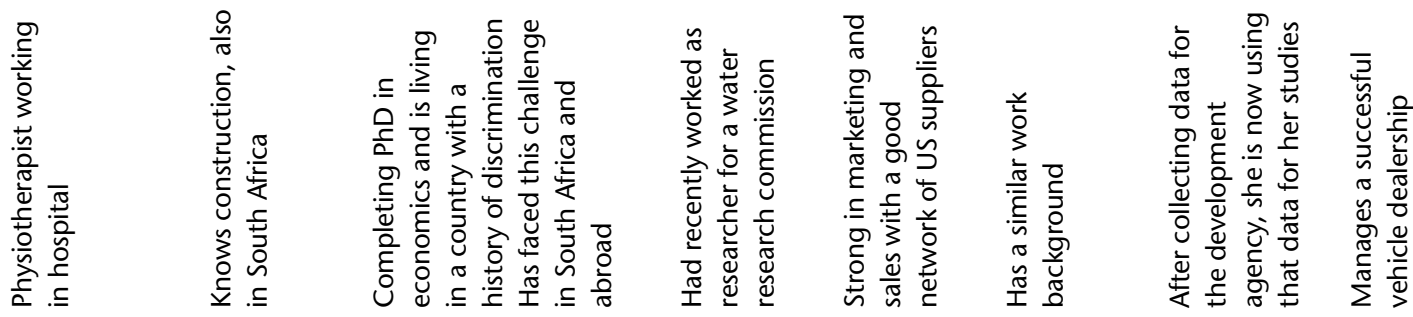

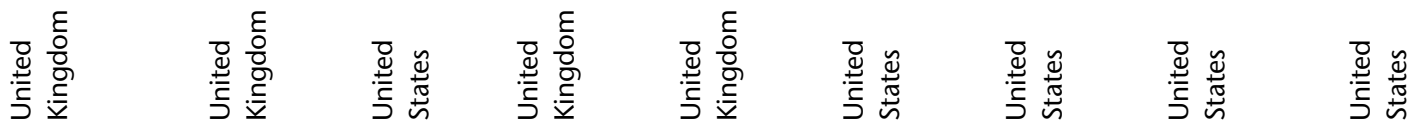

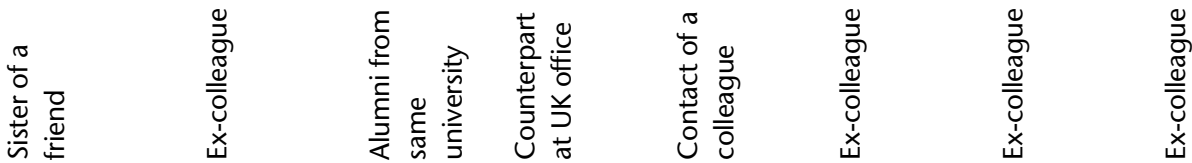

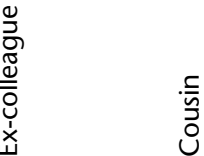

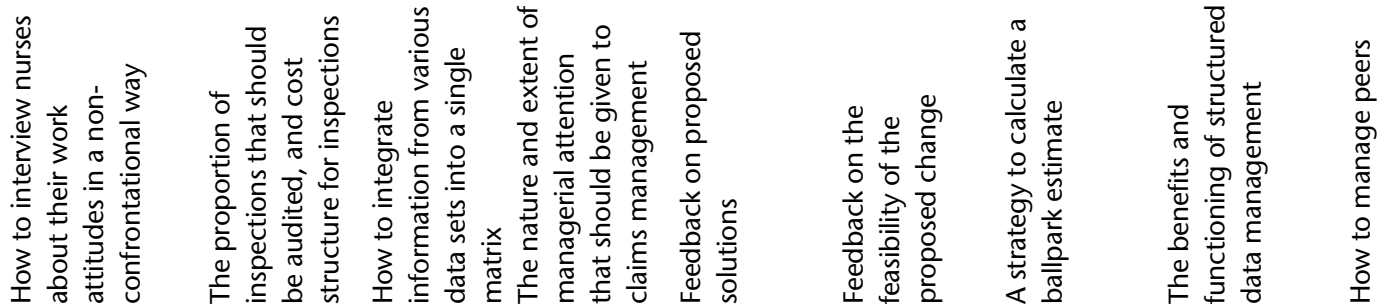

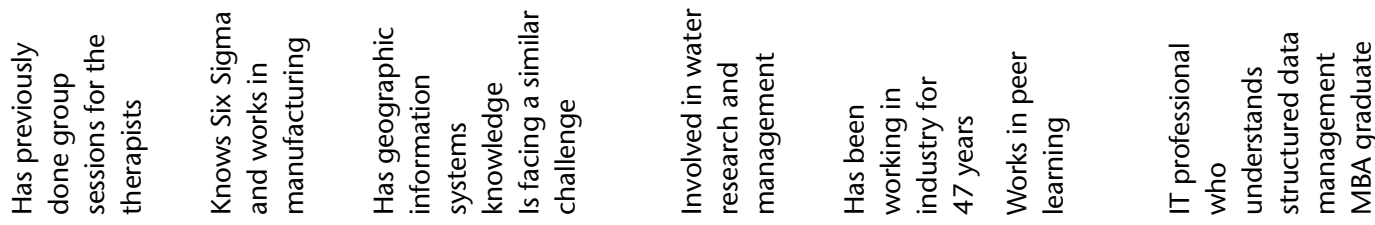

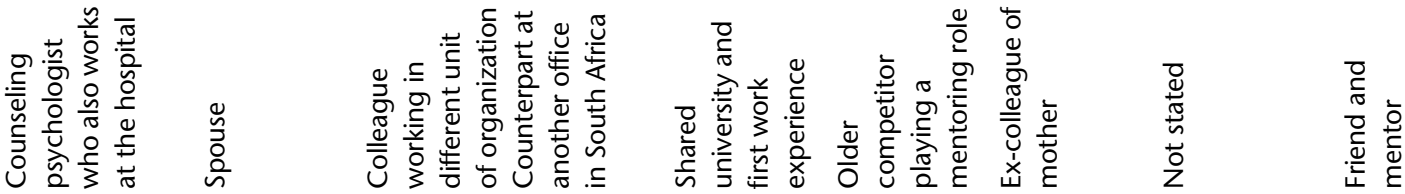

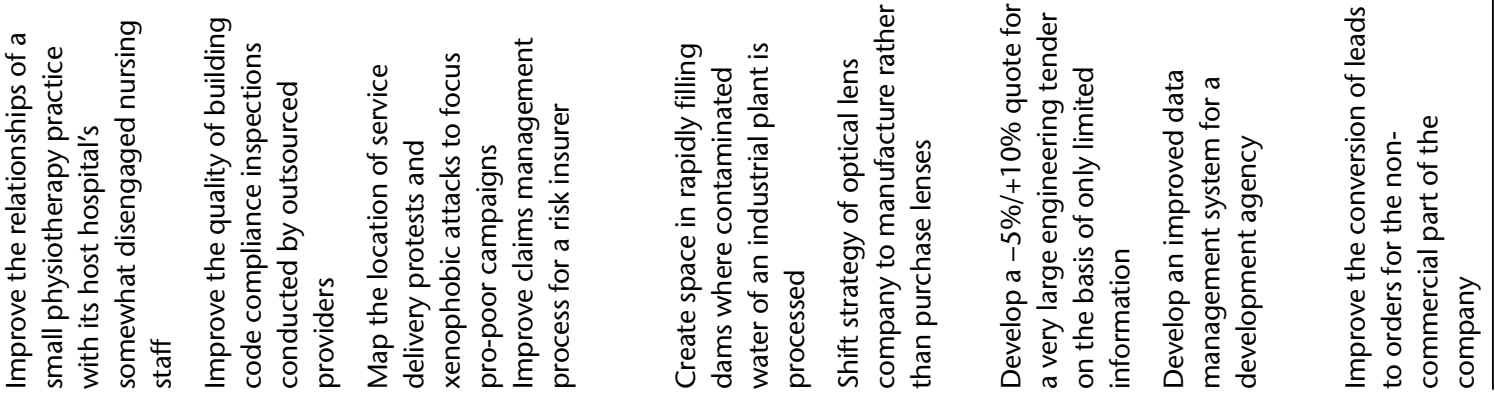


and feedback from a pilot project of 29 managers from another cohort. That pilot proved very useful in demonstrating some of the challenges of doing research in a less-developed context. For example, we initially sought responses concerning four advice providers, but respondents were far less likely to complete questionnaires, and even when they did, the quality of data was often problematic. The challenge of obtaining an acceptable response rate in a less-developed-country context is well documented (Harzing, 2000; Hoskisson, Eden, Lau, \& Wright, 2000). We therefore decided to shorten the survey to reduce the response burden on respondents. In addition, we removed demographic questions and instead had participants fill out an in-class questionnaire with demographic, employment, and other background information. The course instructor reviewed and supplemented the data on organizational size, both for accuracy and for consistency. We also took the decision to ask about only two advice providers, even though respondents were allowed to approach more. That decision has implications for our findings. We do not know whether a given manager contacted more than one advice provider, and if so, why the choice was made to report on a particular one. We presume that respondents completed the survey for their most salient interactions, but it would be interesting for future research to look at the value of different interactions farther down in the pool of potential contacts.

\section{Sample}

Bello, Leung, Radebaugh, Tung, and vanWitteloostuijn (2009) raise two main concerns about student samples: first, that students are often young and inexperienced, especially in terms of international business; and second, that such studies are often classroom exercises or hypothetical scenarios, too far removed from real-life business decisions. Neither of these generalizability concerns, however, applies to the current study. First, we did not include young or inexperienced undergraduates. Rather, our respondents were, on average, 30.3 years old, and had worked in their current job for 2.3 years and current industry for 5.7 years. All were working full time, and their organizations had an average of 19,177 employees, $60.1 \%$ of whom were located abroad. Further enhancing the salience of international business for our respondents was the fact that about half $(49 \%)$ of our respondents had traveled abroad on business in the previous 5 years. In short, these managers had substantial and ongoing work experience, including internationally. Second, our research design was not a classroom or lab exercise; rather, it involved real-life interactions concerning important work projects and decisions. Respondents spent an average of nearly one-third (32\%) of their workday on these work projects, so these work projects required a substantial, real-life time investment. Moreover, the managers in our study did in fact reach out to ties abroad and locally, not just react to a hypothetical scenario. Table 1 suggests that projects were non-trivial, that the managers have a depth of ties both locally and abroad, and that both types of ties have relevant expertise for the type of knowledge sought.

We excluded from our study the small number of non-South African (i.e., foreign) managers (mostly from neighboring African countries), as well as three South Africans who were not working and so could not seek knowledge on a work project. All of the remaining 249 managers were sent an email request to complete the questionnaire, and non-respondents received two or three email reminders. Participants were also asked whether we could use the in-class survey information for the research project. Four managers did not give us permission to use the information, and so we excluded them from our sample. Ultimately, we received completed, valid surveys from 131 managers (response rate $=52.6 \%$ ). This response rate is considered high for a survey in a less-developed country (Hoskisson et al., 2000).

We did not detect any evidence of response bias, as there were no statistically significant differences between respondents and non-respondents for age, gender, race, organization size inside or outside South Africa, industry tenure, or job tenure. In addition, both groups were similar in terms of their experiences abroad in the prior 5 years, for example, in terms of how many business trips abroad they had taken, whether or not they had lived abroad, and among those who had - how long and in how many countries they had lived abroad during those 5 years. The sample's racial breakdown was $46 \%$ White, $41 \%$ Black, 10\% Asian (including Indian), and 2\% "Coloured" (mixed race).

\section{Variables}

\section{Dependent variable}

We measured the receipt of useful knowledge by averaging three items adapted from Levin and Cross (2004). Convergent validity was very high (Cronbach's $\alpha=0.89$ ). We did not try to supplement these self-reports with independent observations (e.g., from supervisors), as third parties are rarely in a 
position to know the details of transferred knowledge, let alone its usefulness. Although recipients and sources might differ in their perceptions of the value of an exchange, our focus was on the knowledge recipients' definitions of value, since "a knowledge seeker is the best, perhaps the only, judge of the usefulness of knowledge received" (Levin \& Cross, 2004: 1482).

We had designed the research in such a way that respondents could approach the most appropriate sources of help, but this introduced the challenge that respondents could approach respondents for different types of knowledge. Given how broad is the construct of "useful knowledge received", we also chose to ask on the survey about the extent to which each contact person provided the respondent with each of the five types of actionable knowledge as identified by Cross and Sproull (2004) - specific answers or input, referrals, problem-solving assistance, validation of ideas, and legitimation - using items adapted from their article. (These five items used the same seven-point scale as our three-item outcome variable.) The three overall items and the five items corresponding to each type of actionable knowledge all loaded onto a single factor - based on principal axis factoring, with eigenvalues of $4.8,0.7$, $0.7,0.5,0.4,0.4,0.3,0.2$, and all factor loadings above 0.5 (average loading of 0.74 ) - thereby suggesting that a single, overall indicator of receipt of useful knowledge would be most appropriate, rather than multiple types of knowledge.

We chose not to create a combined, eight-item scale, as the five types of actionable knowledge had the option of "NA - did not receive anything like this" (which we treated as a missing value), and we were concerned that it might bias the sample to exclude these observations. That is, if a respondent received few or none of the five types of actionable knowledge from someone - and hence chose "NA" for those items - we did not want to exclude that observation, especially since one could argue that such knowledge-transfer interactions are simply low in usefulness and thus should not be excluded. Hence we ultimately used only the three overall items reported above, which did not have an "NA" option.

\section{Independent variables}

For Hypothesis 1 we asked respondents to rate on a 1-7 scale the extent to which their focal project demanded skills, knowledge, and/or expertise that were new to their industry (new-to-the-industry skills needed). For Hypothesis 2 we used a 1-4 scale, adapted from Burt (1992), measuring tie strength as new (i.e., initiated for assignment), distant, inbetween, or extremely close. For Hypothesis 3 we asked respondents to estimate (in minutes) how much time they spent consulting with each person concerning the focal project (related time spent). We then took the logarithm of this estimate, as a logarithm accounts better for how people perceive the passage of time (Currall \& Judge, 1995; Levin, Whitener, \& Cross, 2006; Levin et al., 2011), and it also reduces skewness - in our case, a maximumlikelihood test for the Box-Cox power transformation showed that maximum normality could be attained for our data at $\lambda=0.01$, which is closest to a log transformation (Neter, Kutner, Nachtschiem, \& Wasserman, 1996).

We included a dummy variable, tie abroad (coded as $0=$ local tie, $1=$ tie abroad), which was subsequently multiplied by tie strength (to create tie abroad $\times$ tie strength) and by related time spent (to create tie abroad $\times$ related time spent). These two interaction terms were used to test Hypothesis 2 and Hypothesis 3 (see Analyses subsection below for more details).

\section{Control variables}

To rule out the alternative explanation that it was the communication mode that led to our results, we asked respondents to indicate what percentages of their interactions with each person were via in-person, phone, instant messaging (IM), or email. Since "ipsative" scales (percentages that add up to $100 \%)$ like these cannot be used as predictors in regression or in factor analysis - because they are artificially (negatively) correlated, owing to the nature of the scale - we used multidimensional scaling (MDS) to identify an underlying dimensional structure. Specifically, when we constrained the MDS to a single dimension using the combined sample of contacts abroad and locals, the result was remarkably close to what one would predict a priori based on communication richness theory (Daft \& Lengel, 1986): that is, the four modes were approximately equally spaced. Thus we created a single variable, communication mode richness, where the four ipsative scales are weighted accordingly: $4 \times$ for in-person, $3 \times$ for phone, $2 \times$ for IM, and $1 \times$ for email (see Appendix for more details).

Other controls included variables related to the respondent's demographics (age, gender, race), job history (industry tenure, job tenure), organization (size inside and outside home country), and work project (percentage of workday spent on project; the extent to which project required new skills for the respondent personally, e.g., mastering a personal 
learning need, even if widely known by others in the industry, such as the ability to read financial reports). We also used a two-item measure (with good reliability; Cronbach's $\alpha=0.72$ ) of how much the respondent identified with South Africa or South Africans. This was adapted from an item in Haslam, Oakes, Reynolds, and Turner (1999), since "this item is highly correlated with other global measures of social and organizational identification" (Haslam, 2001: 367).

We also controlled for variables related to the contact person's demographics (gender, race), demographic similarity with the respondent (same race, same gender, same age - to rule out homophily as an alternative explanation), knowing people in common, and having a shared perspective (including a squared term, as prior research suggests that there are benefits and dangers of having too little or too much shared perspective, and so we wanted to capture any potential curvilinear effects fully). To control for several logistic difficulties, we included a dummy variable for communicating with someone several time zones away, and we added an estimate for how much time the respondent spent tracking down the contact person and communicating with him or her about topics not related to the work project. Finally, using the same two social-identity items as before, we asked respondents to estimate how much the contact person identified with South Africa or South Africans (Cronbach's $\alpha=0.85$ ).

\section{Analyses}

Since we have nested data - that is, two knowledgeseeking ties for each respondent - we used hierarchical linear modeling (HLM), a technique that does not rest on the assumption of independent observations (Hofmann, Griffin, \& Gavin, 2000). HLM does, however, require a listwise deletion of missing values, which reduced our usable sample to 233 knowledge-seeking ties and 127 respondents. Following Hofmann (1997), we partitioned the variance in our outcome variable into within- and betweensubject components. A one-way analysis of variance (ANOVA) indicated no significant between-subject variance $\left(\tau_{00}=0.004 ; \quad \chi^{2}[126]=122.15 ; \quad p>0.50\right.$; ICC $=0.003$ ). One concern with using HLM is that it is not possible to test in the usual way any crosslevel interaction - such as with Hypothesis 1 , where a respondent-level variable (new-to-the-industry skills needed) is moderated by a tie-level variable (tie abroad) - if the tie-level variable is a dummy variable with a mean of 0.5 (as in the case of tie abroad). Attempts to test such a cross-level interaction in the usual way will result in a singularity, which prevents the HLM model from converging on a solution. To resolve this problem, we followed Hofmann (personal communication, 2010) and ran a standard two-level model (Hofmann, 1997), specified as follows. The level-1 (in our case, tie-level) equation was:

Receipt of useful knowledge $=\gamma_{0}+\gamma_{1}($ tie abroad $)$

$+\gamma_{2}$ (contact's gender)

$+\gamma_{3}($ contact's race $)$

$+\gamma_{4}$ (same race $)+\gamma_{5}$ (same gender)

$+\gamma_{6}$ (same age)

$+\gamma_{7}$ (communication mode richness)

$+\gamma_{8}($ similar time zone $)$

$+\gamma_{9}$ (contact identifies with home country)

$+\gamma_{10}$ (people in common)

$+\gamma_{11}$ (shared perspective)

$+\gamma_{12}$ (shared perspective squared)

$+\gamma_{13}$ (nonrelated time spent)

$+\gamma_{14}($ related time spent $)+\gamma_{15}($ tie strength $)$

$+\gamma_{16}($ tie abroad $\times$ related time spent $)$

$+\gamma_{17}($ tie abroad $\times$ tie strength $)+$ error

In the above equation, each of the terms were simultaneously predicted by HLM in a series of level-2 (i.e., respondent-level) equations:

$\gamma_{0}=\beta_{00}+\beta_{01}($ respondent's age $)$

$+\beta_{02}$ (respondent's gender)

$+\beta_{03}$ (respondent's race)

$+\beta_{04}$ (respondent's job tenure)

$+\beta_{05}$ (respondent's industry tenure)

$+\beta_{06}$ (respondent's org. size in home country)

$+\beta_{07}$ (respondent's org. size outside home country)

$+\beta_{08}$ (percent of workday spent on project)

$+\beta_{09}$ (new-to-respondent skills needed)

$+\beta_{010}$ (new-to-the-industry skills needed)

$+\beta_{011}$ (respondent identifies with home country)

+ residual $_{0}$

$\gamma_{1}=\beta_{10}+\beta_{11}$ (new-to-the-industry skills needed)

+ residual $_{1}$

$\gamma_{2}=\beta_{20}+$ residual $_{2}$

$\gamma_{3}=\beta_{30}+$ residual $_{3}$

$\gamma_{16}=\beta_{160}+$ residual $_{16}$

$\gamma_{17}=\beta_{170}+$ residual $_{17}$ 
Before testing our hypotheses, we ran a baseline model (Model 1) that did not include the regression terms above for $\gamma_{16}$ and $\gamma_{17}$ (in the level-1 equation and any level-2 equations) or $\beta_{11}$ (in the second level-2 equation). In the full model (Model 2), which is what is shown above, we tested Hypothesis 1 in the second level-2 equation. This equation predicted $\gamma_{1}$, which is the impact on receipt of useful knowledge from contacting a person abroad, and the predictor variable in this equation was the extent to which the respondent needed new-to-the-industry skills (i.e., $\left.\beta_{11}\right)$. This latter term, $\beta_{11}$, was the cross-level interaction effect used to test Hypothesis 1: that is, it indicated the extent to which the level- 2 variable, new-to-the industry skills needed, had a statistically significant impact on the slope of the level-1 variable, tie abroad, in the level-1 equation. We also report below what the intercept $\left(\beta_{10}\right)$ was in this equation that tests Hypothesis 1 (i.e., in the equation predicting $\gamma_{1}$ ). Since Hypothesis 2 and Hypothesis 3 both involve only level-1 variables, we could test them more simply using standard interaction effects: $\gamma_{16}$ for Hypothesis 3 and $\gamma_{17}$ for Hypothesis 2 . We computed $R^{2}$ as (Hofmann 1997: 734):

$$
R^{2}=\frac{\sigma_{\text {one-way ANOVA }}^{2}-\sigma_{\text {random regression }}^{2}}{\sigma_{\text {one-way ANOVA }}^{2}}
$$

\section{RESULTS}

As expected, there was not a significant correlation between the receipt of useful knowledge and whether the knowledge provider was local or abroad $(r=-0.10$; see Table 2$)$ : that is, both types of ties were equally likely to provide useful knowledge to the managers in our sample. To investigate the conditions when contacting a tie abroad is more helpful, we turn to our HLM regression results in Table 3 .

\section{Hypotheses Testing}

All three hypotheses were fully supported. To illustrate our three hypothesized interaction effects, we graphed our results from Table 3's Model 2 in Figures 1-3. In each figure, the horizontal scale ranges from for one standard deviation below the mean to one standard deviation above the mean. As predicted by Hypothesis 1, respondents found it significantly more useful to contact a tie abroad the more they needed new-to-the-industry skills $\left(\beta_{11}\right.$ coefficient $=0.14, p=0.019)$. This is the cross-level interaction effect shown in Table 3's Model 2. Next, as predicted by Hypothesis 2, tie strength significantly moderated the usefulness of contacting a tie abroad $\left(\gamma_{17}\right.$ coefficient $\left.=0.28, p=0.021\right)$ : specifically, the stronger the tie, the more useful it was to contact a tie abroad (and, conversely, the weaker the tie, the more useful it was to contact a local).

Finally, as predicted by Hypothesis 3, related time spent also significantly moderated the usefulness of contacting a tie abroad $\left(\gamma_{16}\right.$ coefficient $=-0.66$, $p=0.015)$. Three aspects are evident in Figure 3: First, both slopes are positive. In general, the longer the interaction discussing the manager's work project, the more useful the interaction was to the manager whether the advice provider was local or abroad. Second, the slope for local ties is twice as steep as that for ties abroad (1.26 vs only 0.60$)$, which means that this effect was significantly greater for interactions with local contacts than it was with contacts abroad. Third, there is a crossover point below which ties abroad provide more value, but beyond which local ties provide more value for a given interaction length. In our sample, using the logged measure, this translated to about $49 \mathrm{~min}$, but obviously this estimate is likely to vary depending on the situation.

\section{Robustness}

Because our respondents provided all of the data for this research, there is a potential for common methods bias. However, moderation effects, as in our study, are less vulnerable to common methods bias, as noted by Brockner, Siegel, Daly, Tyler, and Martin (1997) and others, "because it shows that respondents did not unthinkingly rate all items as either high or low" (Levin \& Cross, 2004: 1482). Moreover, Evans (1985) has concluded, based on a series of Monte Carlo simulations, that if common method variance is present, then the probability of obtaining statistically significant interaction effects is actually reduced, not increased. In addition, a principal components factor analysis of all our level-1 items revealed not one but seven factors with eigenvalues above 1.0, with the largest factor accounting for only $19 \%$ of the total variance, well below the $50 \%$ cut-off for Harman's single-factor test (Podsakoff, MacKenzie, Lee, \& Podsakoff, 2003). In sum, our use of a common method is unlikely to have affected or biased our hypothesized results.

In addition to our tests of the different types of knowledge received, we also asked respondents how codifiable was the knowledge that they received ["All the information/advice I received from this person can be sufficiently explained in writing (in written reports, manuals, emails, faxes, etc.)"; $1=$ none of it, $4=$ half of it, $7=$ all of it], based on items in Hansen (1999) and Levin and Cross (2004). We considered 
Table 2 Means, standard deviations, and correlations

\begin{tabular}{|c|c|c|c|c|c|c|c|c|c|c|c|}
\hline Variable & Mean & SD & 1 & 2 & 3 & 4 & 5 & 6 & 7 & 8 & 9 \\
\hline 1. Receipt of useful knowledge & 5.44 & 1.01 & & & & & & & & & \\
\hline 2. Respondent's age & 30.34 & 4.98 & -0.03 & & & & & & & & \\
\hline 3. Respondent's gender & 0.59 & 0.49 & 0.06 & 0.01 & & & & & & & \\
\hline 4. Respondent's race & 0.46 & 0.50 & 0.05 & -0.05 & -0.03 & & & & & & \\
\hline 5. Respondent's job tenure & 1.29 & 0.41 & -0.10 & $0.36^{* *}$ & -0.05 & -0.03 & & & & & \\
\hline 6. Respondent's industry tenure & 1.74 & 0.32 & -0.03 & $0.62^{\star *}$ & 0.13 & 0.01 & $0.26^{* *}$ & & & & \\
\hline 7. Respondent's org. size in home country & 2.77 & 1.26 & 0.01 & -0.01 & 0.00 & $-0.36^{* *}$ & -0.17 & -0.11 & & & \\
\hline $\begin{array}{l}\text { 8. Respondent's org. size outside home } \\
\text { country }\end{array}$ & 2.08 & 1.92 & -0.08 & $-0.20^{*}$ & 0.02 & $-0.23^{*}$ & $-0.18^{*}$ & -0.14 & $0.65^{* *}$ & & \\
\hline 9. Percentage of workday spent on project & 0.32 & 0.25 & 0.02 & 0.03 & $0.20^{*}$ & -0.10 & 0.03 & 0.15 & 0.16 & 0.02 & \\
\hline 10. New-to-respondent skills needed & 4.23 & 1.40 & 0.07 & 0.01 & 0.00 & 0.12 & 0.02 & -0.10 & -0.16 & $-0.24^{\star *}$ & 0.03 \\
\hline 11. New-to-the-industry skills needed & 3.01 & 1.81 & 0.08 & -0.10 & $-0.18^{*}$ & -0.02 & 0.10 & $-0.19^{*}$ & -0.14 & -0.14 & -0.07 \\
\hline 12. Respondent identifies with home country & 5.98 & 1.18 & 0.06 & -0.10 & 0.02 & -0.17 & $-0.18^{*}$ & -0.02 & $0.25^{\star *}$ & $0.20^{*}$ & 0.00 \\
\hline 13. Tie abroad & 0.49 & 0.50 & -0.10 & 0.01 & -0.03 & 0.01 & 0.01 & -0.01 & -0.02 & 0.00 & -0.01 \\
\hline 14. Contact's gender & 0.73 & 0.45 & 0.00 & -0.02 & $0.23^{* *}$ & 0.01 & -0.04 & 0.06 & -0.12 & 0.07 & 0.12 \\
\hline 15. Contact's race & 0.70 & 0.46 & 0.01 & 0.03 & 0.04 & $0.52^{* *}$ & 0.07 & 0.09 & $-0.28^{\star *}$ & -0.11 & -0.02 \\
\hline 16. Same $r$ & 0.68 & 0.47 & -0.02 & 0.01 & 0.04 & $0.56^{* *}$ & -0.02 & -0.03 & -0.08 & $-0.17^{* *}$ & 0.00 \\
\hline 17. Same & 0.64 & 0.48 & 0.04 & 0.12 & $0.44^{* *}$ & 0.06 & 0.12 & 0.11 & -0.05 & -0.07 & 0.08 \\
\hline 18. Same & 0.42 & 0.49 & -0.08 & 0.04 & -0.01 & 0.01 & -0.01 & 0.05 & 0.05 & -0 & 0.0 \\
\hline 19. Com & 2.42 & 1.08 & 0.13 & 0 . & 0.02 & 0.09 & 0.06 & 0.06 & -0.08 & -0 & 0.02 \\
\hline 20. Simila & 0.73 & 0.45 & 0.05 & -0.09 & 0.00 & -0.10 & 0.04 & -0.02 & -0.05 & -0.07 & -0.04 \\
\hline 21. Contact & 5.52 & 1.21 & $0.22^{\star *}$ & 0.10 & 0.03 & -0.03 & -0.13 & -0.05 & 0.12 & 0.00 & 0.08 \\
\hline 22. People in common & 3.73 & 1.88 & $0.14^{\star}$ & $-0.13^{*}$ & 0.06 & 0.08 & -0.12 & -0.11 & $-0.15^{*}$ & -0.08 & -0.08 \\
\hline 23. Shared pers & 5.46 & 1.40 & $0.24^{* *}$ & -0.01 & 0.07 & $0.23^{* *}$ & -0.03 & 0.09 & $-0.16^{*}$ & $-0.14^{*}$ & 0.01 \\
\hline 24. Shared perspective squared & 1.97 & 3.26 & -0.02 & 0.00 & 0.00 & $-0.17^{\star *}$ & 0.06 & -0.06 & $0.19^{\star *}$ & 0.10 & 0.07 \\
\hline 25. Nonrelated & 1.61 & 0.54 & 0.00 & -0.04 & 0.01 & -0.07 & -0.11 & -0.01 & 0.09 & 0.08 & 0.09 \\
\hline 26. Related time spent & 1.69 & 0.41 & $0.37^{\star \star}$ & 0.05 & -0.04 & 0.05 & $-0.16^{*}$ & -0.09 & 0.07 & -0.08 & -0.01 \\
\hline 27. Tie strer & 2.53 & 0.94 & 0.08 & -0.01 & 0.02 & -0.01 & 0.02 & -0.05 & 0.12 & 0.10 & 0.04 \\
\hline 28. Tie abroad $x$ & -0.04 & 0.28 & $0.15^{*}$ & 0.12 & 0.02 & -0.04 & -0.10 & -0.05 & 0.11 & -0.04 & 0.02 \\
\hline 29. Tie abroad $\times$ Tie strength & -0.14 & 0.69 & $0.14^{*}$ & -0.02 & 0.00 & -0.02 & 0.00 & -0.03 & 0.04 & -0.01 & 0.05 \\
\hline Inavie & 1 & 11 & 12 & 13 & 14 & 15 & 16 & 17 & 18 & 19 & 20 \\
\hline
\end{tabular}

10. New-to-respondent skills needed

11. New-to-the-industry skills needed

12. Respondent identifies with home country

13. Tie abroad

14. Contact's gender

15. Contact's race

16. Same race

17. Same gender

18. Same age

19. Communication mode richness

20. Similar time zone

21. Contact identifies with home country

22. People in common

23. Shared perspective

24. Shared perspective squared

25. Nonrelated time spent

26. Related time spent

27. Tie strength

28. Tie abroad $\times$ Related time spent

29. Tie abroad $\times$ Tie strength

$\begin{array}{rrr}0.18^{*} & & \\ 0.15 & 0.17 & \\ & & \\ 0.01 & 0.01 & -0.01 \\ -0.08 & -0.07 & -0.02 \\ 0.05 & 0.02 & -0.09 \\ 0.10 & 0.00 & -0.09 \\ 0.02 & -0.12 & -0.06 \\ 0.01 & -0.05 & 0.02 \\ 0.09 & 0.05 & -0.05 \\ 0.05 & 0.03 & -0.09 \\ -0.01 & -0.07 & 0.25^{* *} \\ 0.12 & 0.05 & 0.08 \\ 0.07 & -0.01 & -0.05 \\ 0.01 & 0.03 & 0.12 \\ 0.08 & -0.06 & 0.10 \\ 0.08 & 0.06 & 0.15^{*} \\ -0.02 & 0.08 & 0.06 \\ 0.12 & 0.03 & 0.12 \\ 0.05 & 0.10 & 0.03\end{array}$

$-0.14^{*}$

$0.15^{*} \quad 0.13^{*}$

$\begin{array}{lll}-0.11 & -0.08 & -0.04\end{array}$

$\begin{array}{llll}-0.03 & 0.05 & 0.14^{*} & 0.04\end{array}$

$\begin{array}{llll}0.04 & -0.11 & -0.12 & 0.09\end{array}$

$\begin{array}{llll}-0.64^{* *} & 0.08 & -0.06 & 0.09\end{array}$

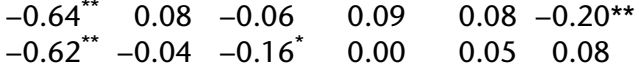

$\begin{array}{lllll}-0.62^{* *}-0.04 & -0.16^{*} & 0.00 & 0.05 & 0.08\end{array}$

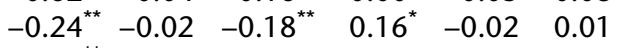

$-0.27^{* \star}$

$-0.13^{*}$

$\begin{array}{ll}0.06 & 0.01\end{array}$

$0.19^{\star *} \quad 0.08$

0.00

$0.14^{*}$

$\begin{array}{lll}-0.14^{*} & -0.02 & 0.00\end{array}$

$\begin{array}{lll}0.00 & 0.01 & -0.05\end{array}$

$\begin{array}{llll}0.05 & -0.10 & -0.04\end{array}$

$\begin{array}{lll}0.11 & 0.04 & 0.19^{* \star}\end{array}$

$\begin{array}{lll}0.06 & -0.03 & 0.07\end{array}$

$\begin{array}{lll}0.06 & 0.02 & 0.22^{* *}\end{array}$
$0.42^{* *}$

$\begin{array}{ll}0.11 & 0.02\end{array}$

$0.22^{* *} 0.22^{* *}$

$0.14^{*} 0.08$

$\begin{array}{ll}-0.06 & -0.03\end{array}$

$\begin{array}{ll}0.09 & -0.07\end{array}$

$0.22^{* *} \quad 0.08$

$0.28^{* *} 0.24^{*}$

$\begin{array}{ll}0.10 & 0.04 \\ 0.20^{* *} & 0.21^{\text {** }}\end{array}$ 


\begin{tabular}{|c|c|c|c|c|c|c|c|c|}
\hline Variable & 21 & 22 & 23 & 24 & 25 & 26 & 27 & 28 \\
\hline 22. People in common & $0.23^{* \star}$ & & & & & & & \\
\hline 23. Shared perspective & $0.21^{\star *}$ & $0.32^{\star *}$ & & & & & & \\
\hline 24. Shared perspective squared & -0.09 & $-0.16^{*}$ & $-0.62^{* *}$ & & & & & \\
\hline 25. Nonrelated time spent & 0.01 & 0.07 & -0.02 & 0.02 & & & & \\
\hline 26. Related time spent & $0.21^{\star *}$ & $0.14^{*}$ & 0.06 & -0.01 & $0.35^{* *}$ & & & \\
\hline 27. Tie strength & $0.21^{\star *}$ & $0.33^{\star \star}$ & $0.21^{\star *}$ & -0.06 & 0.02 & 0.11 & & \\
\hline 28. Tie abroad $\times$ Related time spent & 0.13 & 0.05 & -0.01 & 0.02 & $0.23^{\star *}$ & $0.70^{\star *}$ & 0.11 & \\
\hline 29. Tie abroad $\times$ Tie strength & 0.08 & $0.25^{\star *}$ & $0.16^{*}$ & -0.07 & -0.05 & 0.10 & $0.76^{*}$ & 0.12 \\
\hline
\end{tabular}

$N=233$ for Variables 1 and $13-29 ; N=127$ for Variables $2-12$. Two-tailed tests. ${ }^{*} p<0.05 ;{ }^{* *} p<0.01$.

Table 3 HLM regression results for receipt of useful knowledge

Model 1

Model 2

\begin{tabular}{|c|c|c|c|c|}
\hline \multicolumn{5}{|l|}{ Level-2 variables } \\
\hline Respondent's age & -0.02 & $(0.02)$ & -0.02 & $(0.02)$ \\
\hline Respondent's gender & 0.11 & $(0.13)$ & 0.14 & $(0.13)$ \\
\hline Respondent's race & 0.13 & $(0.18)$ & 0.08 & $(0.18)$ \\
\hline Respondent's job tenure & -0.08 & $(0.14)$ & -0.07 & $(0.14)$ \\
\hline Respondent's industry tenure & 0.29 & $(0.24)$ & 0.23 & $(0.25)$ \\
\hline Respondent's org. size in home country & 0.07 & $(0.07)$ & 0.07 & $(0.07)$ \\
\hline Respondent's org. size outside home country & -0.03 & $(0.04)$ & -0.01 & $(0.04)$ \\
\hline Percentage of workday spent on project & -0.05 & $(0.24)$ & -0.10 & $(0.23)$ \\
\hline New-to-respondent skills needed & 0.03 & $(0.04)$ & 0.03 & $(0.04)$ \\
\hline New-to-the-industry skills needed & 0.05 & $(0.03)$ & -0.02 & $(0.04)$ \\
\hline Respondent identifies with home country & -0.07 & $(0.05)$ & -0.07 & $(0.05)$ \\
\hline \multicolumn{5}{|l|}{ Level-1 variables } \\
\hline Tie abroad & 0.13 & $(0.20)$ & See note below & \\
\hline Contact's gender & -0.06 & $(0.14)$ & -0.07 & $(0.14)$ \\
\hline Contact's race & -0.01 & $(0.16)$ & 0.03 & $(0.16)$ \\
\hline Same race & $-0.30^{\dagger}$ & $(0.16)$ & $-0.25^{\dagger}$ & $(0.15)$ \\
\hline Same gender & 0.11 & $(0.13)$ & 0.12 & $(0.13)$ \\
\hline Same age & $-0.23^{\dagger}$ & $(0.13)$ & $-0.23^{\dagger}$ & $(0.13)$ \\
\hline Communication mode richness & 0.01 & $(0.07)$ & 0.01 & $(0.07)$ \\
\hline Similar time zone & 0.04 & $(0.19)$ & -0.01 & $(0.20)$ \\
\hline Contact identifies with home country & $0.13^{*}$ & $(0.05)$ & $0.14^{*}$ & $(0.06)$ \\
\hline People in common & 0.00 & $(0.03)$ & -0.01 & $(0.03)$ \\
\hline Shared perspective & $0.23^{\star \star \star}$ & $(0.05)$ & $0.24^{* \star *}$ & $(0.05)$ \\
\hline Shared perspective squared & $0.06^{\dagger}$ & $(0.03)$ & $0.06^{*}$ & $(0.03)$ \\
\hline Nonrelated time spent & $-0.25^{*}$ & $(0.12)$ & $-0.23^{\dagger}$ & $(0.12)$ \\
\hline Related time spent & $0.95^{\star \star *}$ & $(0.18)$ & $1.26^{\star \star \star}$ & $(0.22)$ \\
\hline Tie strength & -0.01 & $(0.07)$ & $-0.17^{\dagger}$ & $(0.09)$ \\
\hline Tie abroad $\times$ Related time spent (Hypothesis 3 ) & & & $-0.66^{*}$ & $(0.27)$ \\
\hline Tie abroad $\times$ Tie strength (Hypothesis 2 ) & & & $0.28^{*}$ & $(0.12)$ \\
\hline \multicolumn{5}{|l|}{ Tie abroad $\times$ New-to-the-industry skills needed } \\
\hline Intercept & & & 0.07 & $(0.20)$ \\
\hline Cross-level interaction effect (Hypothesis 1) & & & $0.14^{*}$ & $(0.06)$ \\
\hline$R^{2}$ & \multicolumn{2}{|c|}{0.246} & \multicolumn{2}{|c|}{0.292} \\
\hline Level 1, $N$ & \multicolumn{2}{|c|}{233} & \multicolumn{2}{|c|}{233} \\
\hline
\end{tabular}

Unstandardized coefficients shown, with robust standard errors in parentheses, based on intercepts-as-outcomes (Model 1) and slopes-as-outcomes (Model 2) regression models using HLM. Level 2, N=127 respondents. All variables grand-mean centered, except for tie abroad $(0=$ local tie, $1=$ tie abroad), which is not centered, per Hofmann (personal communication, 2010). Main effect for tie abroad is replaced in Model 2 with an equation that captures the cross-level interaction effect (see Methods section).

${ }^{\dagger} p<0.10 ;{ }^{*} p<0.05 ;{ }^{* *} p<0.01 ;{ }^{* * *} p<0.001$. 


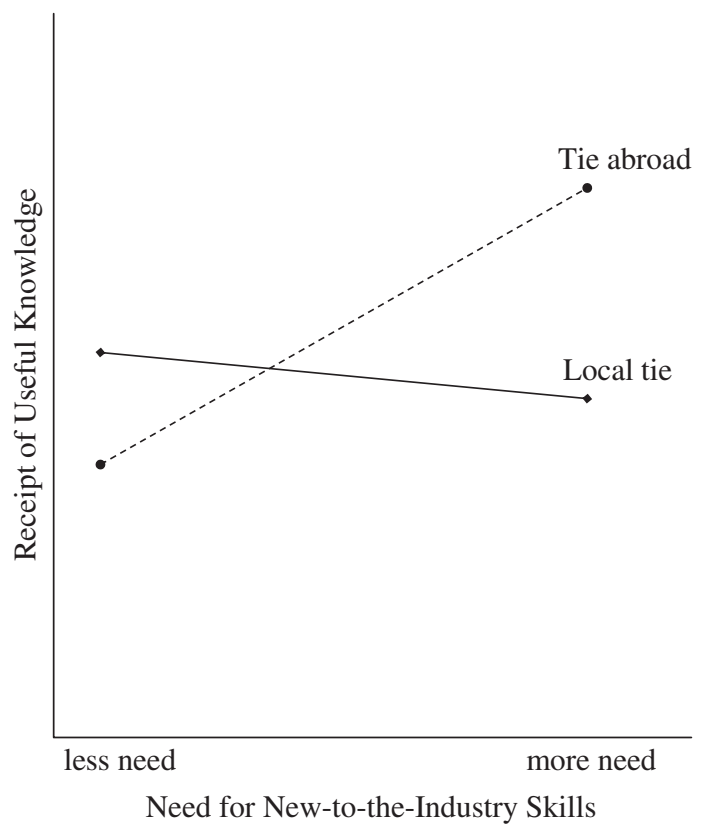

Figure 1 Moderator effect for needing new-to-the-industry skills (Hypothesis 1).

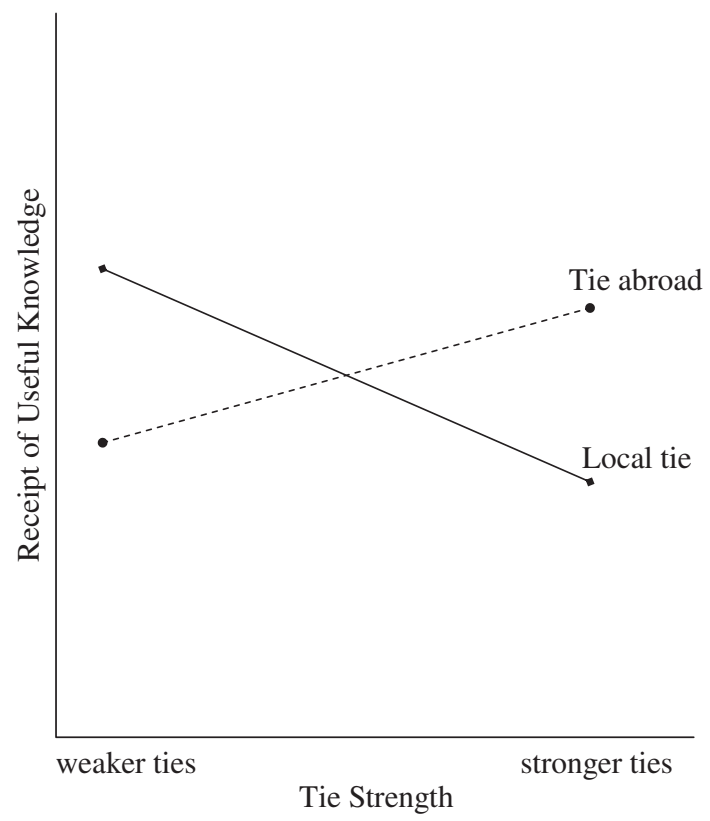

Figure 2 Moderator effect for tie strength (Hypothesis 2).

asking respondents in advance what types of knowledge they were seeking, but - to preserve external validity - we did not want to bias, prime, or constrain them in their knowledge search. Thus we asked only after the fact about what type of knowledge they received, which is not necessarily something that can be predicted ahead of time. If we were to control in HLM for codifiable knowledge and the

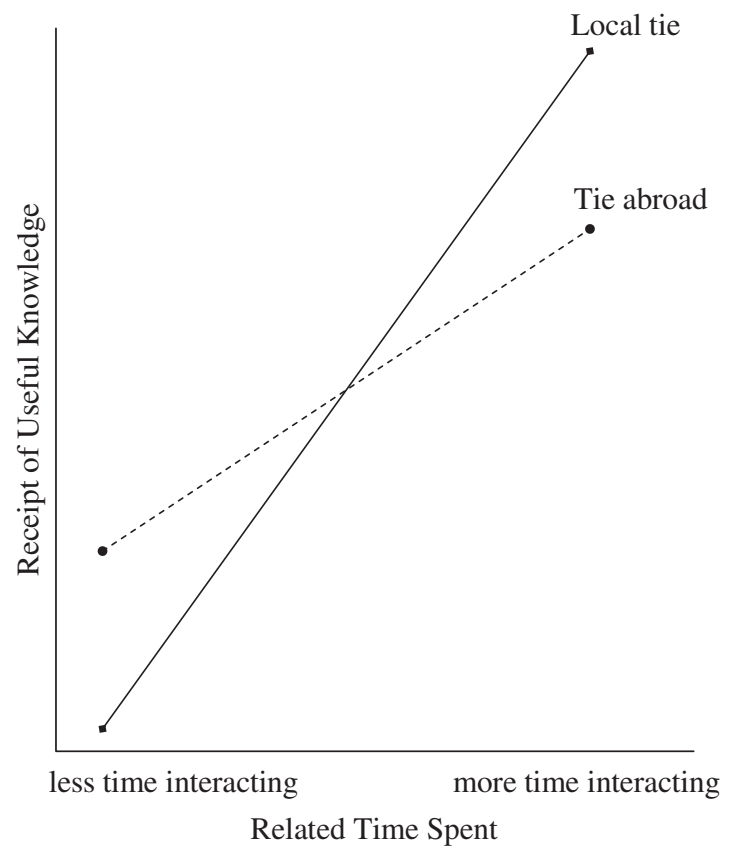

Figure 3 Moderator effect for related time spent (Hypothesis 3).

square of codifiable knowledge - under the (correct, it turns out, at least for our sample) theory that codifiable knowledge might be helpful but too much might become counter-productive - then we find largely similar results: the cross-level interaction effect for Hypothesis 1 becomes marginally significant $(p=0.069)$ but in the same direction, with no change at all to Hypothesis $2(p=0.010)$ or Hypothesis $3(p=0.017)$. Interestingly, we did not find a significant correlation between the type of tie (local vs abroad) and knowledge codifiability ( $r=-0.021$, $p=0.733)$. Thus we are reassured that our results do not seem to differ substantially based on the type of knowledge - be it codifiability (Hansen, 1999) or other typologies (Cross \& Sproull, 2004).

\section{DISCUSSION}

All of our hypotheses were supported. As expected, we did not find a main effect for the benefits of consulting a contact abroad for knowledge: that is, it was not always more useful to contact someone abroad rather than locally. However, we did find support for several boundary conditions for when seeking knowledge from contacts abroad is beneficial. Specifically, it is especially useful to seek knowledge from a contact abroad when the manager is in need of new-to-the-industry knowledge (supporting Hypothesis 1), and also when the manager already has a strong relationship with the contact abroad 
(supporting Hypothesis 2); otherwise, the logistical and other difficulties of obtaining this new knowledge are too great, and we find that the manager would be better off contacting someone locally. Similarly, obtaining additional useful knowledge by having longer interactions was much more successful locally than with contacts abroad (supporting Hypothesis 3).

For years, the dominant models of how international connections facilitate industrial upgrading focused on MNCs establishing high-value-added activities, such as research and development labs, in less-developed countries. The validity of those models is being challenged by the fact that globalization thus far has been characterized by the dispersion of mainly low-value activities, the agglomeration of high-value-adding activities (Leamer \& Storper, 2001; Nachum, 2000; Zaheer \& Manrakhan, 2001), and the realization that the so-called "right" type of FDI is rare (Narula \& Dunning, 2000). The emergence of new poles (e.g., Singapore, China) may counter the trend towards an increased bifurcation of economic activity globally, but it seems likely that many of the less-developed countries will continue to receive less high-value-adding FDI than they may hope for, and that the developed world will remain a powerful magnet for skilled and talented people from the less-developed world, with the associated concerns about a "brain drain".

Against this backdrop, our study presents evidence of an alternative mechanism through which lessdeveloped countries can gain access to useful knowledge, and in so doing, it contributes to the emerging literature on diasporas and migration. It focuses not on connections between firms, but instead on interpersonal connections: how businesspeople in lessdeveloped countries can mobilize their personal links to the developed world. Examples of knowledge seeking in the current study included a stumped mining engineer who contacted an old professor who had since moved to Australia, a marketer who asked a long-time friend from university about digital marketing technology in the United States, and a manager working in the banking industry who contacted a psychologist sister-in-law about change management in dealing with lay-offs after the financial crisis. The frequency of this type of knowledge seeking and providing is not known, but it seems intuitive that such interactions can and do happen, especially when there is a large diaspora community. Moreover, with the rise of social media and global interconnectedness, these interpersonal ties abroad are likely to become even more important.
Whether Mexicans and Vietnamese nationals in the United States, Lebanese and Senegalese nationals in France, or South Africans and Indians in the United Kingdom, it is increasingly common to find people from less-developed countries living in the developed world. Many of those expatriates or emigrants are highly skilled, and research like that of Saxenian (2005) and Liu et al. (2010) documents the positive impact of so-called returnees, that is, migrants who subsequently return to their home country. But many migrants do not return to their country of origin, and the potential contribution of compatriots living abroad is not yet well understood. This study considers the benefits to a (less developed) country of tapping into this pool of potential contacts and finds that such contacts do indeed represent a source of useful, new knowledge.

Thus, through our study, we advance the current research on "brain drain" and "brain circulation". Saxenian (2005) has argued that it may be appropriate to conceptualize the relocation of people from less-developed countries to the developed world as "brain circulation" rather than a "brain drain", as people move between their home and host countries. But whereas her research focuses on the movement of people between countries (and with them, their knowledge), our work examines people who are based in different countries yet share knowledge across national boundaries without leaving those countries. The difference matters: many more people remain settled in a country (whether their country of birth or an adopted country) than continually move. Thus, to the extent that knowledge can be shared remotely, there is a greater possibility of a country benefiting from its diaspora.

Our paper also contributes to an emerging literature on interpersonal networks and international business. The continued globalization of business suggests that an understanding of how interpersonal ties operate internationally as a conduit for the flow of useful business knowledge is likely to become increasingly important. Enderwick (2011) suggests that expatriate employees and immigrant employees are two viable "modes" that firms can use to acquire international knowledge. In the current paper, we suggest a third such mode for knowledge acquisition, namely, to seek knowledge from expatriates and emigrants who are not necessarily fellow employees but who might nonetheless still be willing and able to provide useful knowledge. In other words, we argue that a firm may use interpersonal networks to access knowledge on an as-needed basis, rather than always internalize it through hiring people with the relevant skills. 
The increasing importance of interpersonal ties also introduces new methodological possibilities and challenges to the field. Much of the research on cross-border knowledge transfer has relied on the use of proxies, such as patents (Gittelman, 2008), and fairly indirect measures, which can sometimes be understood in quite different ways. When the unit of analysis is an individual, however, then the analysis can be more precise, and a field such as social psychology offers extensive guidelines for how to approach measurement. Our study moves in this direction, although it, too, is limited in that we measured only a general output construct (the receipt of useful knowledge) and not each specific underlying mechanism, such as novelty. Future research in this vein should therefore push even further in the direction of direct measurement whenever feasible.

This paper investigates where managers should preferentially go - locally or abroad - were they to seek knowledge beyond their current advice network for a given work project. The pool of potential contacts is essentially limitless, but it would not be realistic (or practical) to assess the value of reaching out to every possible knowledge source. We are capturing the very important step of starting to go beyond one's usual advice network for a given work project. We demonstrate that it is unwise to claim that contacts abroad are necessarily better sources of knowledge than local ones (or vice versa). Rather, we provide evidence of several key elements that shape the benefit that can be provided by an advice provider locally vs abroad: the novelty of knowledge sought, the strength of the relationship, and the length of the interaction. However, one of the boundaries of our study is that we do not explore what would happen if managers expanded their search further. As noted earlier, future studies on the depth of the pool of interpersonal ties both abroad and locally would shed further light on the nature and feasibility of knowledge seeking through personal contacts.

Our study also has interesting implications for managers in terms of the time they have available to seek knowledge. Our evidence suggests that when time constraints are critical, managers should seek knowledge abroad, because they will get more usefulness for the limited amount of time they have available. However, if the usefulness of the knowledge exchange is critical (or if the manager has more time to invest), then they are likely to be better off going to a local contact. Although managers gain more useful knowledge from contacts both abroad and locally if they spend more time with them, they gain more "bang for their buck" for every additional hour spent with a local contact.

To pinpoint more precisely the effect of knowledge seeking from same vs different contexts, we hold constant - as part of the research design - that both the knowledge seeker and the knowledge provider are originally from the same country. This, as well as the fact that managers seek advice from compatriots now living in technologically and economically more advanced countries, allows us to explore the potential benefit of a diaspora where knowledge is shared between people with the same nationality but who are living in countries at different levels of development. Although on average, and all else being equal, contacts who live in countries at higher levels of development will have more novel knowledge than locals, there may be specific instances that do not follow this overall trend. For example, a local may have substantial novel knowledge about a particular topic that a contact abroad might not have. However, our focus on compatriots also represents a limitation of the research, as the reality is that people can source knowledge from contacts with a range of different backgrounds. So although our focus in this study has been on managers contacting compatriots living and working abroad, another potential source of knowledge is interpersonal contact with foreigners. For example, a Mexican manager might contact a Spanish executive based either in Mexico or in Spain for knowledge on a particular issue. Anecdotally, we have found examples of both these types of knowledge transfer, and both can work well, suggesting the potential effectiveness of various types of interpersonal ties abroad.

Although our study was motivated by concerns specific to less-developed countries, and empirically tested among managers from such a context, the assumption that contacts from more-developed countries are likely to be the most useful sources of useful knowledge to managers in less-developed countries must also be challenged. First, Enderwick (2011) notes that it is important to consider the type of knowledge sought. Partners with limited technical know-how may still be excellent sources of knowledge about markets and market conditions. Second, as less-developed countries evolve, managers in these countries are likely to have increasingly useful pools of local contacts. Evidence suggests that pockets of excellence are increasingly found in those countries: for example, 
the phenomenon of emerging multinationals (Ramamurti \& Singh, 2009), or certain industries such as the Indian software industry (Athreye, 2005). Thus people in less-developed countries may increasingly benefit from the knowledge of local partners.

Moreover, although the literature generally presumes that little can be learned from engaging with countries at a very low level of development, there is evidence that firms from middle-income countries benefit from engaging with those challenging contexts (e.g., Cuervo-Cazurra \& Genc, 2008). Future work may wish to explore the type and value of knowledge that can be obtained from managers in countries that, relative to the country of origin, are more vs less developed.

Indeed, novelty need not be determined only by technologically more- vs less-advanced contexts. It can simply come from difference. For example, both the United States and Scandinavia are highly developed, but because practices in the two contexts differ, sharing insights with each other may be useful. Such interpersonal ties abroad between advanced economies are likely to be useful, and perhaps especially so when new-to-the-industry knowledge is needed, when there is already a strong tie, and when the knowledge does not require a long and involved interaction. Exploring the value and nature of knowledge seeking from countries at a similar level of development may thus be a fruitful avenue for future research, suggesting that the insights that are gained from the diaspora literature may have wider application.

Our study also provides a unique example of the benefits of "strong bridging ties" (e.g., Levin, Walter, Appleyard, \& Cross, 2013; Tortoriello \& Krackhardt, 2010), that is, relationships that provide both access to new insights (as in "bridges" across organizations, across expertise domains, across social network cliques - and in our case, across different countries) as well as trust and familiarity (as typically occurs with stronger relationships, as we find in Hypothesis 2). Most relationships provide either only new insights or only familiarity, and so it is rare and valuable to find both at the same time. Our focus on contacts abroad as potentially filling this dual role is consistent with prior research on knowledge-seeking relationships in general, but the idea of strong bridging ties has not to our knowledge been demonstrated before in an international context - and especially not at the interpersonal level. Thus our research expands the list of potentially productive ties available to managers seeking useful knowledge.
Finally, our study suggests that the stronger the interpersonal ties, the more effective the knowledge obtained from abroad. In considering how such strong cross-border ties are formed in the first place, anecdotal evidence suggests two main mechanisms: MNCs and migration. Although we have argued that interpersonal networks may provide an alternative to MNCs as a vehicle for obtaining knowledge from abroad, many strong ties abroad are actually formed through an MNC. Stated differently, an MNC is a network not only of subsidiaries, but also of people inside subsidiaries. Thus an obvious implication of our work (and an area for additional research) is that MNCs can improve cross-border communication and coordination by better understanding the interpersonal networks inside the MNC. But our qualitative evidence also suggests that, in some cases, the knowledge seeker (or provider) was no longer working for the MNC - the personal connection had outlived organizational requirements. Such ties had either continued on their own (Corredoira \& Rosenkopf, 2010) or had become dormant but were reconnected for the purpose of seeking knowledge (Levin et al., 2011). A better understanding of the formation and survival of social networks through MNCs may help open the largely black box on spillovers - that is, on how knowledge from the MNC enters the rest of the economy (Rosenkopf \& Almeida, 2003).

This paper also raises important questions about the other important mechanism enabling the formation of strong ties abroad: migration. In our study, some knowledge providers were on temporary work assignments; some were temporary visitors seeking education, "hard" currency, or simply interesting experiences before returning to their home country to settle down; and others had decided to settle permanently in more stable and economically prosperous countries. This diversity is typical of migrant populations (Lucas, 2005), but given the very different motives of the different groups, it has important implications for knowledge transfer. For example, expatriate employees or students are likely to be keen to retain or build a positive reputation at home. In contrast, emigrants are known to experience conflicting emotions - feelings of loyalty to families and friends living in their home country, but also guilt and anger (Svasek, 2008) - and it has been found that those conflicting emotions affect how willingly they share their knowledge (Barnard $\&$ Pendock, 2013). How different types of migrants contribute useful knowledge (or not) is thus another important avenue for future research. 


\section{CONCLUSION}

This paper makes three contributions. First, from an international business perspective, we find that managers in less-developed countries can proactively obtain useful knowledge from the developed world by contacting their compatriots now living abroad, but only under certain conditions. Prior to our study, scholars have known that expatriates and emigrants can serve as a link between countries, but usually in the context of actively forging a connection between their host country and country of origin, such as setting up a factory, working in a joint venture, or other high-involvement activities. In contrast, we find evidence that expatriates and emigrants can serve as a broad-based knowledge resource for managers back home.

Second, we provide evidence of how knowledge is shared across national boundaries through informal, interpersonal networks, finding that the best knowledge providers abroad are strong bridging ties, likely contributing both novelty (because they live in a different country) and trust (because they have strong ties to the knowledge seeker). Although MNCs appear to be an important source of such interpersonal networks, our study demonstrates that MNCs are not the only mechanism through which knowledge can potentially flow internationally.

\section{REFERENCES}

Agndal, H., \& Axelsson, B. 2002. Internationalisation of the firm: The influence of relationship sediments. In V. Havila, M. Forsgren, \& H. Håkansson (Eds), Critical perspectives on internationalisation, 437-456. Oxford: Pergamon Press.

Agrawal, A., Kapur, D., McHale, J., \& Oettl, A. 2011. Brain drain or brain bank? The impact of skilled emigration on poorcountry innovation. Journal of Urban Economics, 69(1): 43-55.

Almeida, P., Phene, A., \& Li, S. 2010. Communities, knowledge, and innovation: Indian immigrants in the US semiconductor industry. GlobAdvantage Center of Research in International Business \& Strategy Working Paper no. 58. http://wwW .globadvantage.ipleiria.pt/files/2010/03/working_paper-58_ globadvantage.pdf, accessed 11 June 2013.

Almeida, P., Hohberger, J., \& Parada, P. 2011. Individual scientific collaborations and firm-level innovation. Industrial and Corporate Change, 20(6): 1571-1599.

Archibugi, D., Denni, M., \& Filippetti, A. 2009. The technological capabilities of nations: The state of the art of synthetic indicators. Technological Forecasting \& Social Change, 76(7): 917-931.

Athreye, S. 2005. The Indian software industry and its evolving service capability. Industrial and Corporate Change, 14(3): 393-418.

Barnard, H., \& Pendock, C. 2013. To share or not to share: The role of affect in knowledge sharing by individuals in a diaspora. lournal of International Management, 19(1): 47-65.

Bell, M., \& Pavitt, K. 1997. Technological accumulation and industrial growth: Contrasts between developed and developing countries. In D. Archibugi, \& J. Michie (Eds), Technology, globalisation and economic performance, 83-137. Cambridge, UK: Cambridge University Press.
Similarly, although many knowledge providers are migrants, we find that knowledge is shared not just if migrants return to their home country, but even without any further migration, through the social networks themselves. These findings contribute to an emerging body of research on diasporas, social networks, and international business.

Third, we develop a more detailed understanding of how the process of cross-border knowledge transfer can occur. We find that knowledge from moredeveloped countries is not always more useful than local knowledge. Put simply: superior results occur mainly when there is a specific need for new knowledge, a motivation to share it, and an ability to overcome the inherent logistical difficulties in obtaining it. This paper thus provides nuanced evidence about both the potential and the limitations of an under-researched mechanism for crossborder knowledge transfer: interpersonal ties abroad.

\section{ACKNOWLEDGEMENTS}

The authors wish to thank Peter Enderwick, Kati Glac, Flocki Taeube, and Jorge Walter for advice and assistance. An earlier version of this paper was presented at the 2011 Academy of Management meetings, San Antonio, TX.

Bello, D., Leung, K., Radebaugh, L., Tung, R.L., \& van Witteloostuijn, A. 2009. From the editors: Student samples in international business research. Journal of International Business Studies, 40(3): 361-364.

Blomström, M., \& Kokko, A. 1998. Multinational corporations and spillovers. Journal of Economic Surveys, 12(2): 1-31.

Bresman, H., Birkinshaw, J., \& Nobel, R. 1999. Knowledge transfer in international acquisitions. Journal of International Business Studies, 30(3): 439-462.

Brockner, J., Siegel, P.A., Daly, J.P., Tyler, T., \& Martin, C. 1997. When trust matters: The moderating effect of outcome favorability. Administrative Science Quarterly, 42(3): 558-583.

Burt, R.S. 1992. Structural holes: The social structure of competition. Cambridge, MA: Harvard University Press.

Chetty, S., \& Agndal, H. 2008. Role of inter-organizational networks and interpersonal networks in an industrial district. Regional Studies, 42(2): 175-187.

Cook, T.D., \& Campbell, D.T. 1979. Quasi-experimentation: Design and analysis issues for field settings. Boston, MA: Houghton Mifflin.

Corredoira, R., \& Rosenkopf, L. 2010. Should auld acquaintance be forgot: The reverse transfer of knowledge through mobility ties. Strategic Management Journal, 31(2): 159-181.

Criscuolo, P. 2005. On the road again: Researcher mobility inside the R\&D network. Research Policy, 34(9): 1350-1365.

Cross, R., \& Sproull, L. 2004. More than an answer: Information relationships for actionable knowledge. Organization Science, 15(4): 446-462.

Cuervo-Cazurra, A., \& Genc, M. 2008. Transforming disadvantages into advantages: Developing-country MNEs in the least 
developed countries. Journal of International Business Studies, 39 (6): 957-979.

Currall, S.C., \& Judge, T.A. 1995. Measuring trust between organizational boundary role persons. Organizational Behavior and Human Decision Processes, 64(2): 151-170.

Daft, R.L., \& Lengel, R.H. 1986. Organizational information requirements, media richness and structural design. Management Science, 32(5): 554-571.

Doner, R.F., Ritchie, B.K., \& Slater, D. 2005. Systemic vulnerability and the origins of developmental states: Northeast and Southeast Asia in comparative perspective. International Organization, 59(2): 327-361.

Driffield, N., Love, J.H., \& Menghinello, S. 2009. The multinational enterprise as a source of international knowledge flows: Direct evidence from Italy. Journal of International Business Studies, 41(2): 350-359.

Ellis, P. 2000. Social ties and foreign market entry. Journal of International Business Studies, 31(3): 443-469.

Ellis, P.D. 2011. Social ties and international entrepreneurship: Opportunities and constraints affecting firm internationalization. Journal of International Business Studies, 42(1): 99-127.

Enderwick, P. 2011. Acquiring overseas market knowledge: A comparison of strategies of expatriate and immigrant employees. Journal of Asia Business Studies, 5(1): 77-97.

Ettlinger, N. 2003. Cultural economic geography and a relational and microspace approach to trusts, rationalities, networks, and change in collaborative workplaces. Journal of Economic Geography, 3(2): 145-171.

Evans, M.G. 1985. A Monte Carlo study of the effects of correlated method variance in moderated multiple regression analysis. Organizational Behavior and Human Decision Processes, 36(3): 305-323.

Filatotchev, I., Liu, X., Buck, T., \& Wright, M. 2009. The export orientation and export performance of high-technology SMEs in emerging markets: The effects of knowledge transfer by returnee entrepreneurs. Journal of International Business Studies, 40(6): 1005-1021.

Flisi, S., \& Murat, M. 2011. The hub continent? Immigrant networks, emigrant diasporas and FDI. Journal of Socio-Economics, 40(6): 796-805.

Gittelman, M. 2008. A note on the value of patents as indicators of innovation: Implications for management research. Academy of Management Perspectives, 22(3): 21-27.

Granovetter, M.S. 1973. The strength of weak ties. American Journal of Sociology, 78(6): 1360-1380.

Gubbi, S.R., Aulakh, P.S., Ray, S., Sarkar, M.B., \& Chittoor, R. 2010. Do international acquisitions by emerging-economy firms create shareholder value? The case of Indian firms. Journal of International Business Studies, 41(3): 397-418.

Hansen, M.T. 1999. The search-transfer problem: The role of weak ties in sharing knowledge across organization subunits. Administrative Science Quarterly, 44(1): 82-111.

Harzing, A. 2000. Cross-national industrial mail surveys: Why do response rates differ between countries? Industrial Marketing Management, 29(3): 243-254.

Haslam, S.A. 2001. Psychology in organizations: The social identity approach. London: Sage.

Haslam, S.A., Oakes, P.J., Reynolds, K.J., \& Turner, J.C. 1999. Social identity salience and the emergence of stereotype consensus. Personality and Social Psychology Bulletin, 25(7): 809-818.

Hofmann, D.A. 1997. An overview of the logic and rationale of hierarchical linear models. Journal of Management, 23(6): 723-744.

Hofmann, D.A., Griffin, M., \& Gavin, M.B. 2000. The application of hierarchical linear modeling to organizational research. In K. Klein, \& S. Kozlowski (Eds), Multilevel theory, research, and methods in organizations, 467-511. San Francisco, CA: Jossey Bass.

Hoskisson, R.E., Eden, L., Lau, C.M., \& Wright, M. 2000. Strategy in emerging economies. Academy of Management Journal, 43 (3): 249-267.

Kaplinsky, R., Chataway, J., Clark, N., Hanlin, R., Kale, D., Muraguri, L., Papaioannou, T., Robbins, P., \& Wamae, W.
2009. Below the radar: What does innovation in emerging economies have to offer other low-income economies? International Journal of Technology Management \& Sustainable Development, 8(3): 177-197.

Kerr, W.R. 2008. Ethnic scientific communities and international technology diffusion. Review of Economics and Statistics, 90(3): 518-537.

Kim, L. 1998. Crisis construction and organizational learning: Capability building in catching-up at Hyundai Motor. Organization Science, 9(4): 506-521.

Lall, S. 1998. Exports of manufactures by developing countries: Emerging patterns of trade and location. Oxford Review of Economic Policy, 14(2): 54-73.

Lall, S. 2001. Competitiveness, technology and skills. Cheltenham, UK: Edward Elgar.

Leamer, E.E., \& Storper, M. 2001. The economic geography of the internet age. Journal of International Business Studies, 32(4): 641-665.

Levin, D.Z., \& Cross, R. 2004. The strength of weak ties you can trust: The mediating role of trust in effective knowledge transfer. Management Science, 50(11): 1477-1490.

Levin, D.Z., Whitener, E.M., \& Cross, R. 2006. Perceived trustworthiness of knowledge sources: The moderating impact of relationship length. Journal of Applied Psychology, 91(5): 1163-1171.

Levin, D.Z., Walter, J., \& Murnighan, J.K. 2011. Dormant ties: The value of reconnecting. Organization Science, 22(4): 923-939.

Levin, D.Z., Walter, J., Appleyard, M.M., \& Cross, R. 2013. Relational enhancement: How the relational dimension of social capital unlocks the value of network-bridging ties. Working paper, Rutgers Business School, Rutgers University, Newark, NJ.

Liu, X., Lu, J., Filatotchev, I., Buck, T., \& Wright, M. 2010. Returnee entrepreneurs, knowledge spillovers and innovation in high-tech firms in emerging economies. Journal of International Business Studies, 41(7): 1183-1197.

London, T., \& Hart, S.L. 2004. Reinventing strategies for emerging markets: Beyond the transnational model. Journal of International Business Studies, 35(5): 350-370.

Lucas, R.E.B. 2005. International migration and economic development. Cheltenham, UK: Edward Elgar.

Madhavan, R., \& Iriyama, A. 2009. Understanding global flows of venture capital: Human networks as the "carrier wave" of globalization. Journal of International Business Studies, 40(8): 1241-1259.

Marin, A., \& Bell, M. 2006. Technology spillovers from foreign direct investment (FDI): The active role of MNC subsidiaries in Argentina in the 1990s. Journal of Development Studies, 42(4): 678-697.

McDermott, G.A., \& Corredoira, R.A. 2010. Network composition, collaborative ties, and upgrading in emerging-market firms: Lessons from the Argentine autoparts sector. Journal of International Business Studies, 41(2): 308-329.

Meyer, K.E., \& Sinani, E. 2009. When and where does foreign direct investment generate positive spillovers? A meta-analysis. Journal of International Business Studies, 40(7): 1075-1094.

Mullings, B. 2011. Diaspora strategies, skilled migrants and human capital enhancement in Jamaica. Global Networks, 11(1): 24-42.

Nachum, L. 2000. Economic geography and the location of TNCs: Financial and professional service FDI to the USA. Journal of International Business Studies, 31(3): 367-385.

Narula, R., \& Dunning, J.H. 2000. Industrial development, globalization and multinational enterprises: New realities for developing countries. Oxford Development Studies, 28(2): 141-167.

Neter, J., Kutner, M.H., Nachtschiem, C.J., \& Wasserman, W. 1996. Applied linear statistical models, 4th edn. Chicago, IL: Irwin.

Oddou, G.R., \& Mendenhall, M.E. 1991. Succession planning for the 21st century: How well are we grooming our future business leaders? Business Horizons, 34(1): 26-34.

Oettl, A., \& Agrawal, A. 2008. International labor mobility and knowledge flow externalities. Journal of International Business Studies, 39(8): 1242-1260.

Podsakoff, P.M., MacKenzie, S.B., Lee, J.-Y., \& Podsakoff, N.P. 2003. Common method biases in behavioral research: A critical 
review of the literature and recommended remedies. Journal of Applied Psychology, 88(5): 879-903.

Ramamurti, R., \& Singh, J.V. 2009. Emerging multinationals in emerging markets. Cambridge, UK: Cambridge University Press.

Riddle, L., \& Brinkerhoff, J. 2011. Diaspora entrepreneurs as institutional change agents: The case of Thamel.com. International Business Review, 20(6): 670-680.

Rosenkopf, L., \& Almeida, P. 2003. Overcoming local search through alliances and mobility. Management Science, 49(6): 751-766.

Saxenian, A. 2002. Transnational communities and the evolution of global production networks: The cases of Taiwan, China and India. Industry and Innovation, 9(3): 183-202.

Saxenian, A. 2005. From brain drain to brain circulation: Transnational communities and regional upgrading in India and China. Studies in Comparative International Development, 40(2): 35-61.

Saxenian, A. 2006. The new argonauts: Regional advantage in a global economy. Cambridge, MA: Harvard University Press.

Saxenian, A., \& Hsu, J.-Y. 2001. The Silicon Valley-Hsinchu connection: Technical communities and industrial upgrading. Industrial and Corporate Change, 10(4): 893-920.

\section{Appendix}

\section{Survey Items}

Receipt of useful knowledge

(1) Overall contribution to your performance on your work project. (2) Overall contribution to the success of your work project. (3) Overall contribution to helping you deliver a better work project. ( 1 =contributed very negatively; $2=$ contributed negatively; 3 =contributed somewhat negatively; $4=$ contributed neither positively nor negatively; $5=$ contributed somewhat positively; $6=$ contributed positively; $7=$ contributed very positively.) Note: If the project that you identified is ongoing, then answer the questions based on the help that the person has given you so far. [Average of three items, Cronbach's $\alpha=0.89$.]

\section{Respondent's age}

Year born [recoded as years until survey date].

\section{Respondent's gender}

$0=$ female; $1=$ male.

Respondent's race

[Gauged by instructor, coded as $0=$ Black, Coloured, Indian, or Other; $1=$ White.]

\section{Respondent's job tenure}

Number of years in specific organization you work for [recoded as logarithm of: months $(+1)$ ].

\section{Respondent's industry tenure}

Number of years in industry [recoded as logarithm of: months $(+1)]$.
Svasek, M. 2008. Who cares? Families and feelings in movement. Journal of Intercultural Studies, 29(3): 213-230.

Szulanski, G., \& Jensen, R.J. 2006. Presumptive adaptation and the effectiveness of knowledge transfer. Strategic Management Journal, 27(10): 937-957.

Tortoriello, M., \& Krackhardt, D. 2010. Activating cross-boundary knowledge: The role of Simmelian ties in the generation of innovations. Academy of Management Journal, 53(1): 167-181.

Vang, J., \& Overby, M.L. 2006. Transnational communities, offshore outsourcing and offshore subsidiaries: The case of the Indian IT industry. In B.-A. Lundvall, P. Intarakumnerd, \& J. Vang (Eds), Asia's innovation systems in transition, 54-74. Cheltenham, UK: Edgar Elgar.

Zaheer, S., \& Manrakhan, S. 2001. Concentration and dispersion in global industries: Remote electronic access and the location of economic activities. Journal of International Business Studies, 32(4): 667-686.

Zhao, Z., Anand, J., \& Mitchell, W. 2004. Transferring collective knowledge: Teaching and learning in the Chinese auto industry. Strategic Organization, 2(2): 133-167.

Respondent's org. size in home country

Approximate number of people employed by your organization (i.e., size) in South Africa? [Adjusted by instructor based on external data, recoded as logarithm of: number of employees +1 .]

Respondent's org. size outside home country

Approximate number of people employed by your organization (i.e., size) worldwide excluding South Africa? [Adjusted by instructor based on external data, recoded as logarithm of: number of employees +1 .]

\section{Percentage of workday spent on project}

On average, what percentage of a normal work day do you spend on this work project?

\section{New-to-respondent skills needed}

To what extent does this project demand skills, knowledge, and/or expertise that are new for you personally? $(1=$ not at all; $7=$ to a very large extent $)$

New-to-the-industry skills needed

To what extent does this project demand skills, knowledge, and/or expertise that are new for your industry? $(1=$ not at all; $7=$ to a very large extent)

Respondent identifies with home country

(1) Being associated with South Africa (the country) is important to me; (2) Being associated with South Africans (as a group) is important to me. (1=strongly disagree; $2=$ disagree; $3=$ somewhat disagree; $4=$ neutral; $5=$ somewhat agree; $6=$ agree; $7=$ strongly agree) [Average of two items, Cronbach's $\alpha=0.72$.] 
Tie abroad

$(0=$ South African living and working in South Africa; $1=$ South African living and working abroad)

Contact's gender

What is each person's gender? $(0=$ female; $1=$ male $)$

Contact's race

What is each person's race? [Recoded as $0=$ Black, Coloured, Indian, or Asian; $1=$ White.]

Same race

[Calculated as $0=$ different race; $1=$ same race as respondent.]

\section{Same gender}

[Calculated as $0=$ different gender; $1=$ same gender as respondent.]

\section{Same age}

What is each person's age? (younger than me by $5+$ years; my age plus or minus 5 years; older than me by $5+$ years; don't know) [Recoded as $0=$ different age; $1=$ same age as respondent.]

\section{Communication mode richness}

Estimate how much you used each communication mode (in percentages, adding up to $100 \%$ ) to interact with each person: in person [multiplied by weighting of 4] + phone [multiplied by 3] + IM [multiplied by 2] + email [multiplied by 1]; Other (please specify) [recoded "Skype" $(n=1)$ and "conference call" $(n=1)$ as phone; "Facebook" as half IM and half email $(n=4)$; and "fax" $(n=1)$ as email]. [Variable calculated as weighted sum; weightings are consistent with results of MDS constrained to a single dimension.]

\section{Similar time zone}

Type in each person's current location (country). [Countries coded as $0=$ North America or Oceania; $1=$ Europe, Israel, or South Africa.]

Contact identifies with home country

If I were to estimate, I would say that... (1) Being associated with South Africa (the country) is important to this person; (2) Being associated with South Africans (as a group) is important to this person. (1=strongly disagree; [etc.]; $7=$ strongly agree) [Average of two items, Cronbach's $\alpha=0.85$.]

\section{People in common}

You and this person are in contact with the same people (i.e., you two have interpersonal networks that completely overlap). $(1=$ not at all; $7=$ to a very large extent)

\section{Shared perspective}

You and this person share the same perspective (e.g., thinking alike, similar goals, understanding each other's language/jargon) ( $1=$ strongly disagree; [etc.]; 7 = strongly agree)

\section{Nonrelated time spent}

If you were to add it up, about how much time did you spend... (1) Tracking down this person? (2) Talking with this person about things unrelated to your project (during discussions where your project was discussed)? (in minutes) [Recoded as logarithm of: tracking minutes+unrelated minutes +1 .]

\section{Related time spent}

If you were to add it up, about how much time did you spend ... Consulting with this person concerning your project? (in minutes) [Recoded as logarithm of: minutes +1 .]

\section{Tie strength}

You and this person have the following relationship with each other $(0=$ new (initiated for assignment); 1 = distant; 2 =in-between; 3 = extremely close)

\section{About the Authors}

Daniel Z Levin is Associate Professor at Rutgers Business School - Newark and New Brunswick at Rutgers University. He received his PhD at Northwestern University's Kellogg School. His research is on knowledge transfer and advice seeking, especially the role of current and dormant relationships, social networks, and interpersonal trust. He has previously published in Organization Science, Management Science, MIT Sloan Management Review, and elsewhere.

Helena Barnard is Associate Professor at the Gordon Institute of Business Science (GIBS) at the University of Pretoria. She received her PhD from Rutgers University. She researches the role of both local and foreign connectedness in the upgrading of developing countries, and has investigated how it functions in emerging multinationals, in cross-national scientific collaborations, and through interpersonal ties. 